\title{
Information operator approach applied to the retrieval of the vertical distribution of atmospheric constituents from ground-based high-resolution FTIR measurements
}

\author{
C. Senten, M. De Mazière, G. Vanhaelewyn, and C. Vigouroux \\ Belgian Institute for Space Aeronomy (BIRA-IASB), Ringlaan 3, 1180 Brussels, Belgium \\ Correspondence to: C. Senten (cindy.senten@ aeronomie.be)
}

Received: 5 April 2011 - Published in Atmos. Meas. Tech. Discuss.: 14 June 2011

Revised: 8 November 2011 - Accepted: 22 December 2011 - Published: 16 January 2012

\begin{abstract}
The analysis of high spectral resolution Fourier Transform infrared (FTIR) solar absorption spectra is an important issue in remote sensing. If this is done carefully, one can obtain information, not only about the total column abundances, but also about the vertical distribution of various constituents in the atmosphere. This work introduces the application of the information operator approach for extracting vertical profile information from ground-based FTIR measurements. The algorithm is implemented and tested within the well-known retrieval code SFIT2, adapting the optimal estimation method such as to take into account only the significant contributions to the solution. In particular, we demonstrate the feasibility of the method in an application to ground-based FTIR spectra taken in the framework of the Network for the Detection of Atmospheric Composition Change (NDACC) at Ile de La Réunion $\left(21^{\circ} \mathrm{S}, 55^{\circ} \mathrm{E}\right)$. A thorough comparison is made between the original optimal estimation method, Tikhonov regularization and this alternative retrieval algorithm, regarding information content, retrieval robustness and corresponding full error budget evaluation for the target species ozone $\left(\mathrm{O}_{3}\right)$, nitrous oxide $\left(\mathrm{N}_{2} \mathrm{O}\right)$, methane $\left(\mathrm{CH}_{4}\right)$, and carbon monoxide $(\mathrm{CO})$. It is shown that the information operator approach performs well and in most cases yields both a better accuracy and stability than the optimal estimation method. Additionally, the information operator approach has the advantage of being less sensitive to the choice of a priori information than the optimal estimation method and Tikhonov regularization. On the other hand, in general the Tikhonov regularization results seem to be slightly better than the optimal estimation method and information operator approach results when it comes to error budgets and column stability.
\end{abstract}

\section{Introduction}

Since 2002 the Belgian Institute for Space Aeronomy (BIRA-IASB) has been responsible for measurements of high-resolution ground-based FTIR solar absorption spectra at the Observatoire de Physique de l'Atmosphère de La Réunion (OPAR). This station is located at $21^{\circ} \mathrm{S}, 55^{\circ} \mathrm{E}$, in the Indian Ocean, East of Madagascar, at the edge between the southern tropics and subtropics and it is coordinated by the Laboratoire de l'Atmosphère et des Cyclones (LACy) of the Universite de La Réunion. These FTIR observations contribute to the worldwide survey of the evolution of the atmospheric composition and structure, in the framework of NDACC (Kurylo and Solomon, 1990; Kurylo, 1991). It is therefore fundamental to extract as much information as possible about the vertical distribution of the target atmospheric constituents absorbing within the FTIR spectral ranges, and to make sure that the knowledge gained is reliable. The vertical profile information can be derived from the line shape of the absorption lines via the altitude dependence of the pressure broadening.

The analyses shown here focus on the atmospheric species ozone $\left(\mathrm{O}_{3}\right)$, nitrous oxide $\left(\mathrm{N}_{2} \mathrm{O}\right)$, methane $\left(\mathrm{CH}_{4}\right)$ and carbon monoxide (CO). These gases have been selected for several reasons. First, they are mandatory species within the NDACC Infrared Working Group (IRWG), because of their important roles in tropospheric and stratospheric chemistry and their link to current environmental problems like climate change and stratospheric ozone depletion. Second, at Ile de La Réunion, $\mathrm{CO}$ is an important tracer of biomass burning. Additional arguments to study these trace gases are that they have different numbers of degrees of freedom for signal

Published by Copernicus Publications on behalf of the European Geosciences Union. 
(Sect. 2.2.2) and that they are very much wanted for satellite validation.

Within the NDACC IRWG it is common to use the optimal estimation method (OEM) (Rodgers, 2000) or Tikhonov regularization (TR) (Tikhonov, 1963) to solve the inverse problem. Nevertheless, in some cases one may encounter problems like vertical profile instability or physically unrealistic retrieval results. Looking for a more robust inversion method in order to eliminate these difficulties has led us to the information operator approach (IOA) (Doicu et al., 2007), which has been proved successful for the inversion of satellite data by Hoogen et al. (1999). The fact that the IOA is by definition based on the genuine information content of the measurements makes it presumable that the method improves the stability of the retrievals - avoiding spurious profile oscillations -, that it gives a more realistic idea of the actual information content that can be acquired, and that it generates smaller error budgets. As the IOA has never before been applied to spectra measured from the ground, it is very useful to test its feasibility for ground-based FTIR observations and to verify its possibilities with respect to the OEM and TR. In order to perform the retrievals of the above-mentioned trace gases with the IOA, we implemented this new algorithm into the retrieval code SFIT2 (v3.94), jointly developed at the NASA Langley Research Center, the National Center for Atmospheric Research (NCAR) and the National Institute of Water and Atmosphere Research (NIWA) (Rinsland et al., 1998; Hase et al., 2004).

The paper is organised as follows: Sect. 2 provides a theoretical description of the IOA retrieval method, while Sect. 3 shows the retrieval results and error budget evaluations for the target species obtained from the above mentioned FTIR spectra, when applying the OEM, IOA and TR. Section 4 discusses the influence of the a priori information on the OEM, IOA and TR results. Section 5 describes a theoretical study of the three methods based on synthetic spectra. Conclusions are given in Sect. 6 .

\section{General description of the information operator approach}

The problem we are facing is the retrieval of the vertical distribution of target atmospheric species from ground-based high-resolution solar absorption spectra. The commonly used algorithm, SFIT2, is based on a semi-empirical implementation of the OEM of Rodgers (2000). Applying the IOA onto the OEM is an efficient way of automatically using only those components of the measurements that effectively contribute to the final information content, prior to knowing how much information you can get and where it is situated. How this can be achieved is explained in Sect. 2.2.

\subsection{Forward model}

The forward model in SFIT2 is a multi-layer multi-species line-by-line radiative transfer model and remains unchanged when applying the IOA. The instrument parameters in the forward model include a wavenumber scale multiplier and background curve parameters, as well as the actual optical path difference and field of view of the instrument. To account for deviations from the ideal instrument line shape (ILS) function due to small instrument misalignments or imperfections, empirical apodization and phase error functions are included in the forward calculations. These calculations are executed on a fine altitude grid to take into account the local atmospheric pressure and temperature variabilities.

\subsection{Inverse model}

The inverse problem consists of determining the best representation of the true state of the atmosphere from the observed absorption spectra, more specifically, the vertical distributions and total column amounts of the target molecules. In order to solve this ill-posed problem, some regularization within the ensemble of possible solutions is required. To enhance the performance of the standard SFIT2 retrieval code, results from information theory can be taken into account explicitly. We now present the theoretical background of this adapted optimal estimation scheme incorporating the IOA, as well as its implementation in the SFIT2 algorithm.

\subsubsection{Adapted retrieval method}

First note that the retrieval of vertical profiles from FTIR data is an underconstrained problem, because of the following reasons: (1) a profile is a continuous function of altitude, whereas an FTIR spectrometer provides measurements only at a discrete number of wavelengths; and (2) there are components in the actual profile which do not contribute to the measurements and, consequently, cannot be determined from them. In order to numerically solve the inverse problem, the profile is discretized to a finite number of height levels between which it is assumed to be a linear function of altitude. Additional information is needed to get a physically reasonable result. In particular, when using the OEM, a priori knowledge about the atmospheric trace gas distributions is used to adequately constrain the retrieved profile.

Since the vector of transmittances of the observed solar absorption spectrum within the ranges of the fitted microwindow(s) is a nonlinear function of the atmospheric state, the retrieval solution has to be found iteratively. In the iteration step $i+1$ the optimal estimation solution can be written as (Rodgers, 2000):

$$
\begin{aligned}
\boldsymbol{x}_{i+1} & =\boldsymbol{x}_{\mathrm{a}}+\left(\mathbf{K}_{i}^{\mathrm{T}} \mathbf{S}_{y}^{-1} \mathbf{K}_{i}+\mathbf{S}_{\mathrm{a}}^{-1}\right)^{-1} \mathbf{K}_{i}^{\mathrm{T}} \mathbf{S}_{y}^{-1}\left[\boldsymbol{y}-\boldsymbol{y}_{i}\right. \\
& \left.+\mathbf{K}_{i}\left(\boldsymbol{x}_{i}-\boldsymbol{x}_{\mathrm{a}}\right)\right],
\end{aligned}
$$

where $\boldsymbol{x}_{\mathrm{a}}$ is the a priori atmospheric state vector (of dimension $N), \mathbf{S}_{\mathrm{a}}$ is the a priori covariance matrix, $\boldsymbol{y}$ is the 
(a)

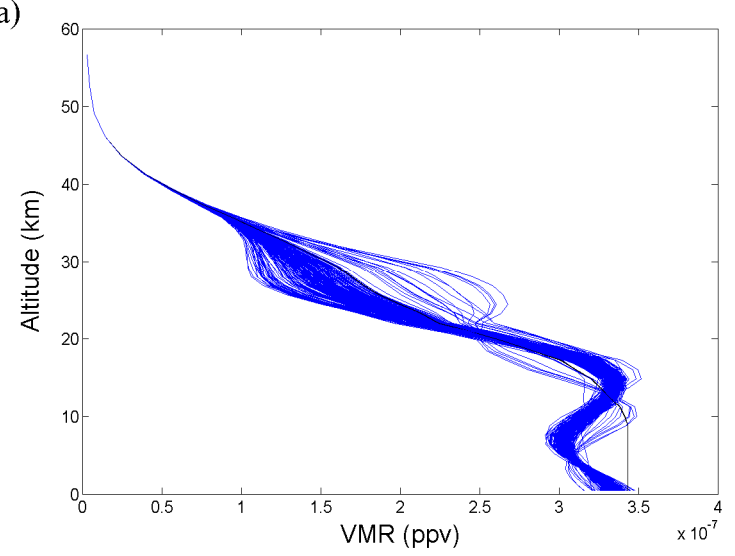

(c)

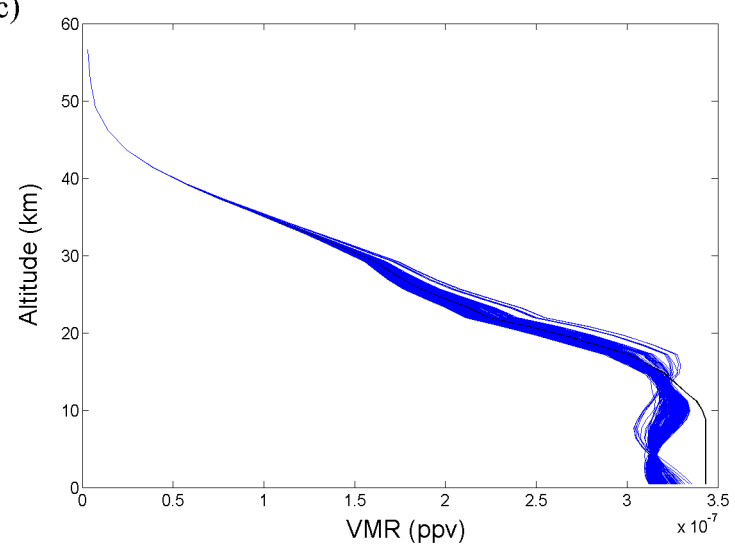

(b)

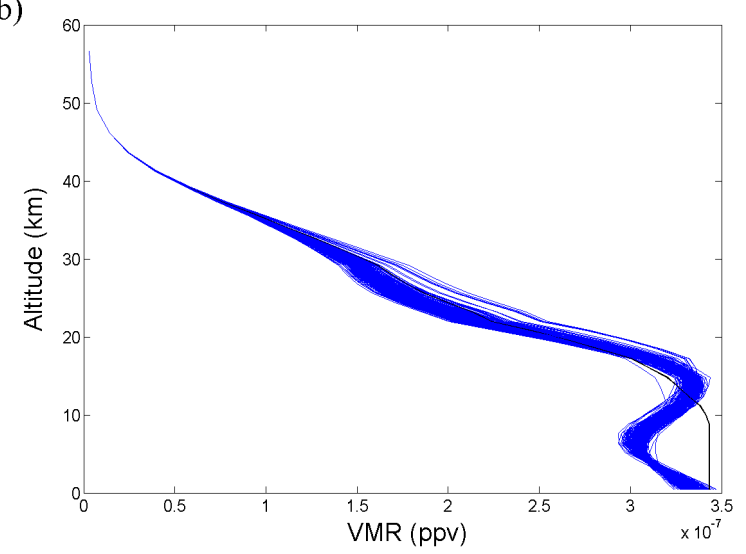

(d)

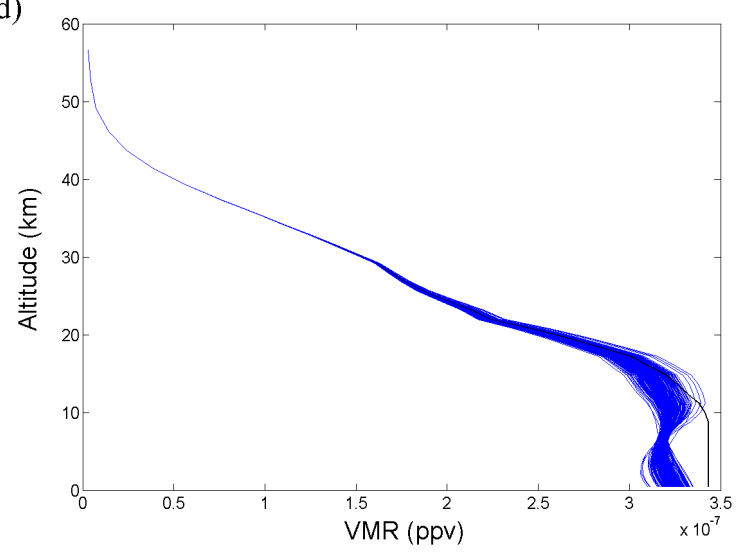

Fig. 1. $\mathrm{N}_{2} \mathrm{O}$ profiles from all spectra taken at St.-Denis during the 2007 campaign, retrieved with the (a) OEM and with the IOA with threshold (b) 0.09 , (c) 0.79 and (d) 0.99 , respectively. The black line corresponds to the a priori profile used.

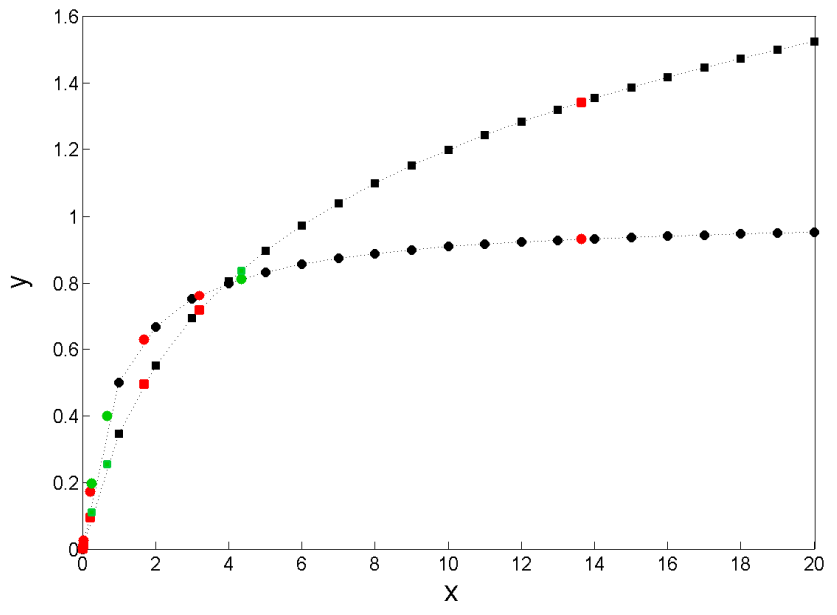

Fig. 2. Curves of $y=x /(1+x)$ (black circles) and $y=1 / 2 \ln (1+x)$ (black squares) for $x$ between 0 and 20 and for the eigenvalues of $\mathbf{P}_{\mathrm{r}}$ that lay within this domain, for $\mathrm{O}_{3}$ (red) and $\mathrm{CO}$ (green). measurement vector (of dimension $M$ ), $\boldsymbol{y}_{i}$ is the same quantity calculated by the forward model using the result $\boldsymbol{x}_{i}$ from the previous iteration $i, \mathbf{S}_{y}$ is the measurement error covariance matrix, and $\mathbf{K}_{i}$ is the weighting function matrix, defined as $\delta \boldsymbol{y} / \delta \boldsymbol{x}$, after the i-th iteration. When convergence has occurred, the result of the last iteration is identified with the retrieval solution $\boldsymbol{x}_{\mathrm{r}}$. The corresponding solution covariance matrix is then given by (Rodgers, 2000):

$\mathbf{S}_{\mathrm{r}}=\left(\mathbf{K}_{\mathrm{r}}^{\mathrm{T}} \mathbf{S}_{y}^{-1} \mathbf{K}_{\mathrm{r}}+\mathbf{S}_{\mathrm{a}}^{-1}\right)^{-1}$.

As mentioned in Sect. 2.1, $\boldsymbol{y}$ is not only influenced by the target species' absorption but also by several other parameters, such as the background curve and wavelength shift parameters, the empirical apodization and phase error polynomial function parameters, and the interfering species' absorptions. By including these additional fit parameters in the state vector $\boldsymbol{x}$, the target profile retrievals can be improved significantly. Note that the number of elements in $x$ is much larger than the number of independent elements that can be retrieved from the measurement. Moreover, in practice, the number of independent retrieved parameters is even smaller due to inevitable measurement noise. Theoretically, 
Table 1. Retrieval characteristics for each target species, for the 2007 FTIR campaign at Ile de La Réunion. The variances represent the diagonal elements of $\mathbf{S}_{\mathrm{a}}$ and HWHM the applied inter-layer correlation length of a Gaussian probability distribution. The last three columns list the spectral micro-windows that are fitted simultaneously, the associated spectral resolution (depending on the optical filter and on the target gas), and the main interfering species, respectively.

\begin{tabular}{|c|c|c|c|c|c|}
\hline Molec. & Variance $[\%]$ & HWHM [km] & Micro-window(s) $\left[\mathrm{cm}^{-1}\right]$ & Resol. $\left[\mathrm{cm}^{-1}\right]$ & Interf. species \\
\hline $\mathrm{O}_{3}$ & 10 & 4 & $1000.00-1005.00$ & 0.0072 & $\mathrm{H}_{2} \mathrm{O}, \mathrm{CO}_{2}, \mathrm{C}_{2} \mathrm{H}_{4}, \mathrm{O}_{3}^{668}, \mathrm{O}_{3}^{686}$ \\
\hline $\mathrm{N}_{2} \mathrm{O}$ & 10 & 5 & $\begin{array}{l}2481.30-2482.60 \\
2526.40-2528.20 \\
2537.85-2538.80 \\
2540.10-2540.70\end{array}$ & 0.00513 & $\mathrm{CO}_{2}, \mathrm{CH}_{4}, \mathrm{O}_{3}, \mathrm{H}_{2} \mathrm{O}, \mathrm{HDO}$ \\
\hline $\mathrm{CH}_{4}$ & variable* & 5 & $\begin{array}{l}2613.70-2615.40 \\
2650.60-2651.30 \\
2835.50-2835.80 \\
2903.60-2904.03 \\
2921.00-2921.60\end{array}$ & 0.00513 & $\mathrm{HDO}, \mathrm{H}_{2} \mathrm{O}, \mathrm{CO}_{2}, \mathrm{NO}_{2}$ \\
\hline $\mathrm{CO}$ & 20 & 4 & $\begin{array}{l}2057.70-2057.91 \\
2069.55-2069.72 \\
2140.40-2141.40 \\
2157.40-2159.20 \\
2165.37-2165.85 \\
2168.84-2169.02\end{array}$ & 0.0036 & $\mathrm{O}_{3}, \mathrm{OCS}, \mathrm{CO}_{2}, \mathrm{~N}_{2} \mathrm{O}, \mathrm{H}_{2} \mathrm{O}$, solar $\mathrm{CO}$ lines \\
\hline
\end{tabular}

* Ranging from 4 to $70 \%$, as a function of altitude.

Table 2. Evolution of $1 / 2 \ln \left(1+\lambda_{\mathrm{r}, n}\right)$ and $\lambda_{\mathrm{r}, n} /\left(1+\lambda_{\mathrm{r}, n}\right)$ for the largest 24 eigenvalues $\lambda_{\mathrm{r}, n}$ of the Kozlov information matrix $\mathbf{P}_{\mathrm{r}}$, for $\mathrm{O}_{3}$, $\mathrm{N}_{2} \mathrm{O}, \mathrm{CH}_{4}$ and $\mathrm{CO}$.

\begin{tabular}{|c|c|c|c|c|c|c|c|c|}
\hline \multirow[b]{2}{*}{$n$} & \multicolumn{2}{|c|}{$\mathrm{O}_{3}$} & \multicolumn{2}{|c|}{$\mathrm{N}_{2} \mathrm{O}$} & \multicolumn{2}{|c|}{$\mathrm{CH}_{4}$} & \multicolumn{2}{|c|}{$\mathrm{CO}$} \\
\hline & $1 / 2 \ln \left(1+\lambda_{\mathrm{r}, n}\right)$ & $\lambda_{\mathrm{r}, n} /\left(1+\lambda_{\mathrm{r}, n}\right)$ & $1 / 2 \ln \left(1+\lambda_{\mathrm{r}, n}\right)$ & $\lambda_{\mathrm{r}, n} /\left(1+\lambda_{\mathrm{r}, n}\right)$ & $1 / 2 \ln \left(1+\lambda_{\mathrm{r}, n}\right)$ & $\lambda_{\mathrm{r}, n} /\left(1+\lambda_{\mathrm{r}, n}\right)$ & $1 / 2 \ln \left(1+\lambda_{\mathrm{r}, n}\right)$ & $\lambda_{\mathrm{r}, n} /\left(1+\lambda_{\mathrm{r}, n}\right)$ \\
\hline 1 & 17.3168 & 1.0000 & 15.6414 & 1.0000 & 15.4139 & 1.0000 & 15.5225 & 1.0000 \\
\hline 2 & 11.3409 & 1.0000 & 9.0650 & 1.0000 & 15.3273 & 1.0000 & 15.3972 & 1.0000 \\
\hline 3 & 7.1326 & 1.0000 & 6.1980 & 1.0000 & 15.0916 & 1.0000 & 15.0273 & 1.0000 \\
\hline 4 & 6.8262 & 1.0000 & 5.4902 & 1.0000 & 14.5332 & 1.0000 & 14.4747 & 1.0000 \\
\hline 5 & 4.7069 & 0.9999 & 4.9038 & 0.9999 & 14.4930 & 1.0000 & 14.3777 & 1.0000 \\
\hline 6 & 4.5662 & 0.9999 & 4.7459 & 0.9999 & 11.0533 & 1.0000 & 13.8888 & 1.0000 \\
\hline 7 & 4.2232 & 0.9998 & 4.3099 & 0.9998 & 7.0866 & 1.0000 & 11.9066 & 1.0000 \\
\hline 8 & 3.7078 & 0.9994 & 4.2361 & 0.9998 & 4.8829 & 1.0000 & 8.5702 & 1.0000 \\
\hline 9 & 2.8993 & 0.9970 & 4.0495 & 0.9997 & 4.4885 & 0.9999 & 6.5113 & 1.0000 \\
\hline 10 & 2.6263 & 0.9948 & 3.9281 & 0.9996 & 4.4172 & 0.9999 & 5.8351 & 1.0000 \\
\hline 11 & 2.3000 & 0.9899 & 3.6862 & 0.9994 & 4.1455 & 0.9999 & 5.7922 & 1.0000 \\
\hline 12 & 1.3416 & 0.9317 & 3.3634 & 0.9988 & 3.4401 & 0.9997 & 5.5019 & 1.0000 \\
\hline 13 & 0.7166 & 0.7615 & 2.9367 & 0.9972 & 3.3155 & 0.9990 & 5.1528 & 1.0000 \\
\hline 14 & 0.4941 & 0.6278 & 2.7310 & 0.9958 & 2.3465 & 0.9987 & 4.6797 & 0.9999 \\
\hline 15 & 0.0942 & 0.1717 & 2.4667 & 0.9928 & 2.0997 & 0.9908 & 4.4398 & 0.9999 \\
\hline 16 & 0.0133 & 0.0262 & 2.1979 & 0.9877 & 1.4615 & 0.9850 & 4.2783 & 0.9998 \\
\hline 17 & 0.0031 & 0.0062 & 0.9955 & 0.8634 & 1.4586 & 0.9462 & 3.8915 & 0.9996 \\
\hline 18 & 0.0023 & 0.0046 & 0.3338 & 0.4871 & 0.0342 & 0.1469 & 2.5302 & 0.9937 \\
\hline 19 & 0.0003 & 0.0006 & 0.0869 & 0.1595 & 0.0342 & 0.1469 & 2.3931 & 0.9917 \\
\hline 20 & 0.00007 & 0.0001 & 0.0840 & 0.1546 & 0.0060 & 0.0120 & 2.0579 & 0.9837 \\
\hline 21 & 0.000006 & 0.00001 & 0.0124 & 0.0244 & 0.0060 & 0.0120 & 1.7362 & 0.9690 \\
\hline 22 & 0.000003 & 0.000006 & 0.0012 & 0.0023 & 0.0002 & 0.0004 & 0.8377 & 0.8128 \\
\hline 23 & 0.0000009 & 0.000002 & 0.0001 & 0.0003 & 0.0002 & 0.0004 & 0.2552 & 0.3998 \\
\hline 24 & 0.00000006 & 0.0000001 & 0.0001 & 0.0003 & 0.00004 & 0.00007 & 0.1099 & 0.1973 \\
\hline
\end{tabular}


(a)

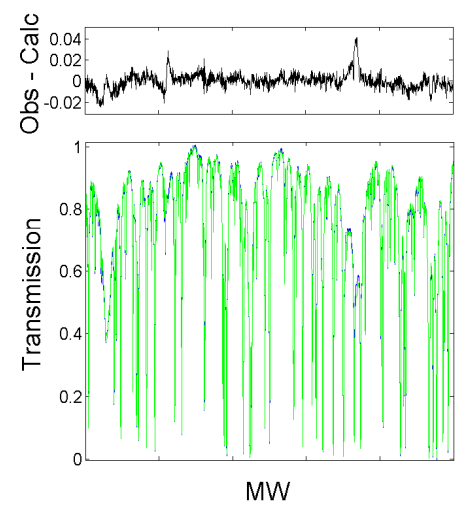

(b)

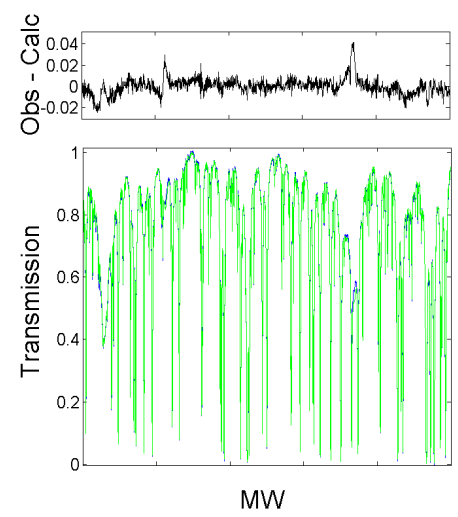

(c)
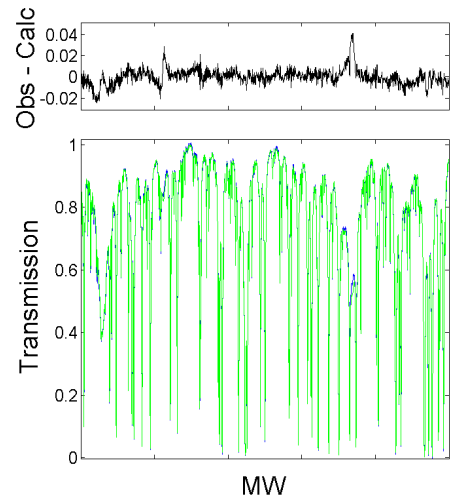
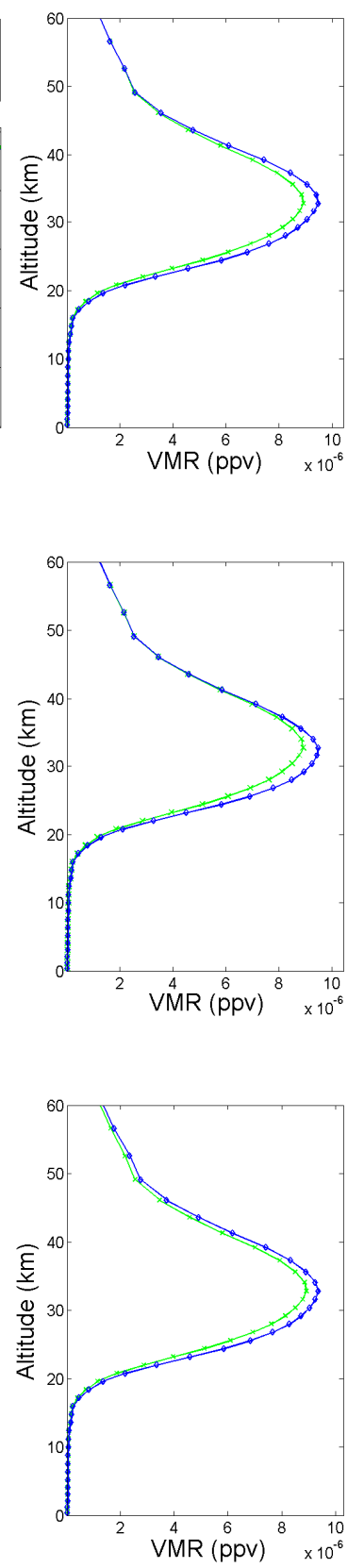

Fig. 3. Single micro-window $\left(1000.00-1005.00 \mathrm{~cm}^{-1}\right)$ fit of $\mathrm{O}_{3}$ plus interfering species from a single spectrum on 12 September 2007 at St.-Denis using the (a) OEM, (b) IOA and (c) TR. Measured (blue) and simulated (green) spectra are shown (left lower plot), together with the residuals (left upper plot), computed as measured minus simulated. The right plot shows the a priori (green crosses) and retrieved (blue diamonds) profile.

(a)

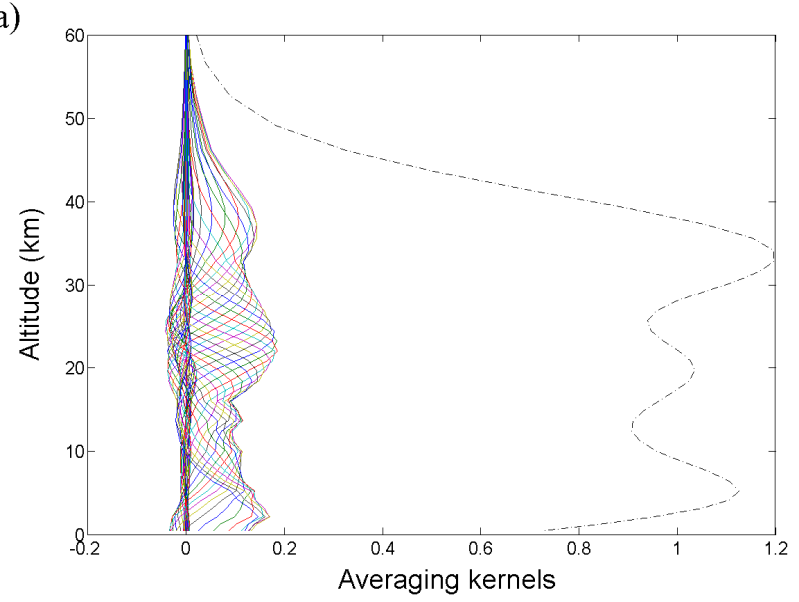

(b)

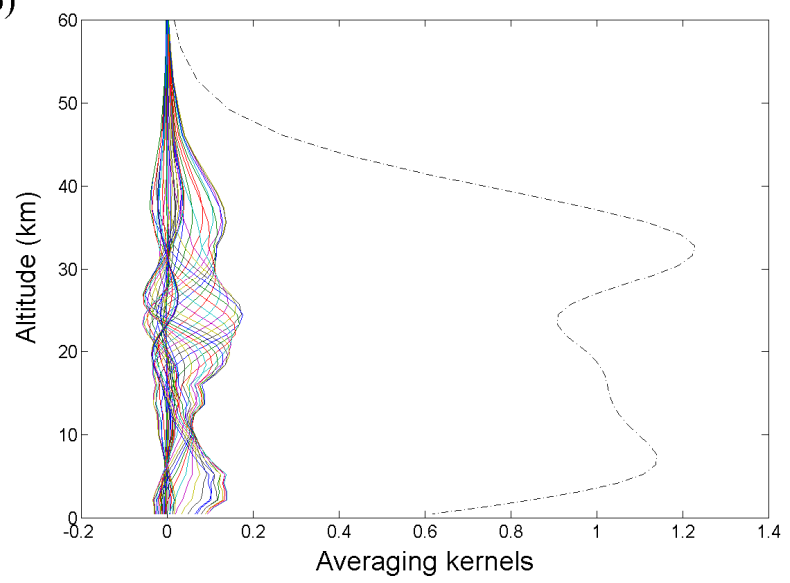

(c)

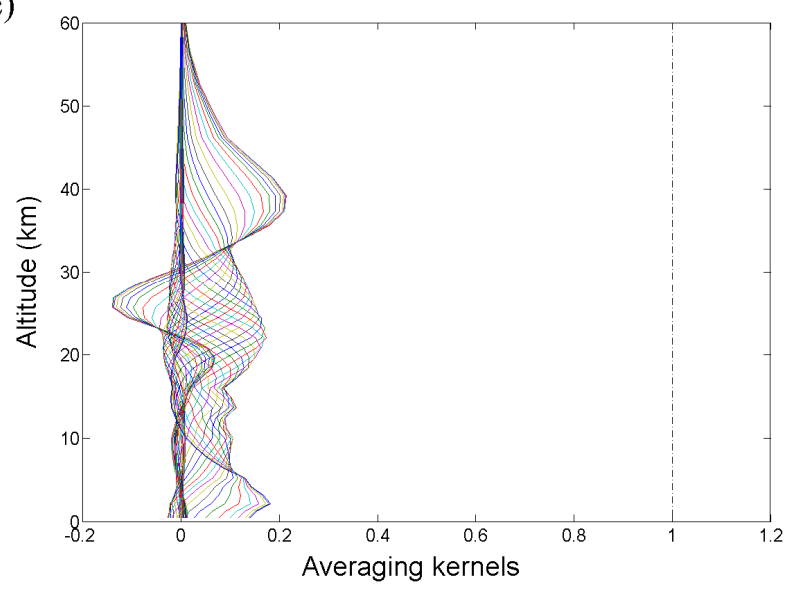

Fig. 4. Averaging kernels and sensitivity curve (black dashed) for the $\mathrm{O}_{3}$ retrieval from a single spectrum on 12 September 2007 at St.-Denis using the (a) OEM, (b) IOA and (c) TR. 
the information content of the measurement can be defined as the reduction in entropy of the a posteriori knowledge about the atmospheric state with respect to the a priori knowledge (Shannon and Weaver, 1949). Under the assumption that $\boldsymbol{x}_{\mathrm{a}}$ and $\boldsymbol{x}_{\mathrm{r}}$ are Gaussian distributed, the information content $H$ of a measurement can be shown to be (Rodgers, 2000):

$H=1 / 2 \ln \left[\operatorname{det}\left(\mathbf{S}_{\mathrm{a}}\right)\right]-1 / 2 \ln \left[\operatorname{det}\left(\mathbf{S}_{\mathrm{r}}\right)\right]$.

Using the definition $\mathbf{P}_{\mathrm{r}}=\mathbf{S}_{\mathrm{a}} \mathbf{G}_{\mathrm{r}}$, with $\mathbf{G}_{\mathrm{r}}=\mathbf{K}_{\mathrm{r}}^{\mathrm{T}} \mathbf{S}_{y}^{-1} \mathbf{K}_{\mathrm{r}}$, Eq. (3) can be rewritten as:

$$
\begin{aligned}
H & =1 / 2 \ln \left[\operatorname{det}\left(\mathbf{S}_{\mathrm{a}} \mathbf{S}_{\mathrm{r}}^{-1}\right)\right] \\
& =1 / 2 \ln \left[\operatorname{det}\left(\mathbf{P}_{\mathrm{r}}+\mathbf{I}\right)\right] \\
& =1 / 2 \sum_{n=1}^{N} \ln \left(\lambda_{\mathrm{r}, n}+1\right),
\end{aligned}
$$

where $\lambda_{\mathrm{r}, n}(n=1, \ldots, N)$ are the eigenvalues of the $N \times N$ matrix $\mathbf{P}_{\mathrm{r}}$, the so-called "Kozlov information matrix" (Kozlov, 1983). These eigenvalues thus represent the information content in the measurement, while the corresponding eigenvectors form a basis for the solution space. Hence, only the $N_{\text {opt }}$ eigenvalues with a relevant contribution to the information content, i.e. $1 / 2 \ln \left(\lambda_{\mathrm{r}, n}+1\right) \geq 1$ or $\lambda_{\mathrm{r}, n} /\left(1+\lambda_{\mathrm{r}, n}\right) \approx$ $1\left(n=1, \ldots, N_{\text {opt }} \leq N\right)$, should be taken into account. The associated eigenvectors $\phi_{\mathrm{r}, n}\left(n=1, \ldots, N_{\text {opt }}\right)$ span the effective state space accessible with the measurement. Therefore, the IOA retrieval results directly depend on the information content of the measurement by expanding - in each iteration - the difference between the a priori and the true state vector into a series of the significant eigenvectors of $\mathbf{P}_{i}$. This gives the following equation:

$\boldsymbol{x}_{i+1}-\boldsymbol{x}_{\mathrm{a}}=\sum_{n=1}^{N_{\text {opt }}} \beta_{i, n} \boldsymbol{\phi}_{i, n}$.

Now, instead of the state vector $\boldsymbol{x}_{i+1}$ itself, the coefficients $\beta_{i, n}$ have to be determined. In Hoogen et al. (1999) some straightforward calculations lead to the derivation of the expansion coefficients $\beta_{i, n}\left(n=1, \ldots, N_{\text {opt }}\right)$ :

$$
\begin{aligned}
\beta_{i, n} & =\lambda_{i, n} /\left[N_{i, n}\left(1+\lambda_{i, n}\right)\right] \boldsymbol{\phi}_{i, n}^{\mathrm{T}} \mathbf{K}_{i}^{\mathrm{T}} \mathbf{S}_{y}^{-1}\left[\boldsymbol{y}-\boldsymbol{y}_{i}\right. \\
& \left.+\mathbf{K}_{i}\left(\boldsymbol{x}_{i}-\boldsymbol{x}_{\mathrm{a}}\right)\right],
\end{aligned}
$$

where $N_{i, n}=\boldsymbol{\phi}_{i, n}^{\mathrm{T}} \mathbf{K}_{i}^{\mathrm{T}} \mathbf{S}_{y}^{-1} \mathbf{K}_{i} \quad \boldsymbol{\phi}_{i, n} \quad\left(n=1, \ldots, \quad N_{\text {opt }}\right) \quad$ are normalization factors defined as such.

In our implementation the calculation of the eigenvectors and eigenvalues of $\mathbf{P}_{i}$ is based on the common QR method (Golub and Van Loan, 1983), i.e. the matrix $\mathbf{P}_{i}$ is iteratively decomposed into the product of an orthogonal matrix $\mathbf{Q}$ and an upper triangular matrix $\mathbf{R}$, until the method converges and all eigenvalues and eigenvectors are determined. As the repeated QR factorizations can be quite expensive, the real non-symmetric matrix $\mathbf{P}_{i}$ is first reduced to the simpler upper Hessenberg form, i.e. having zero entries below the first subdiagonal, and then the similarity transformations are accumulated. (a)
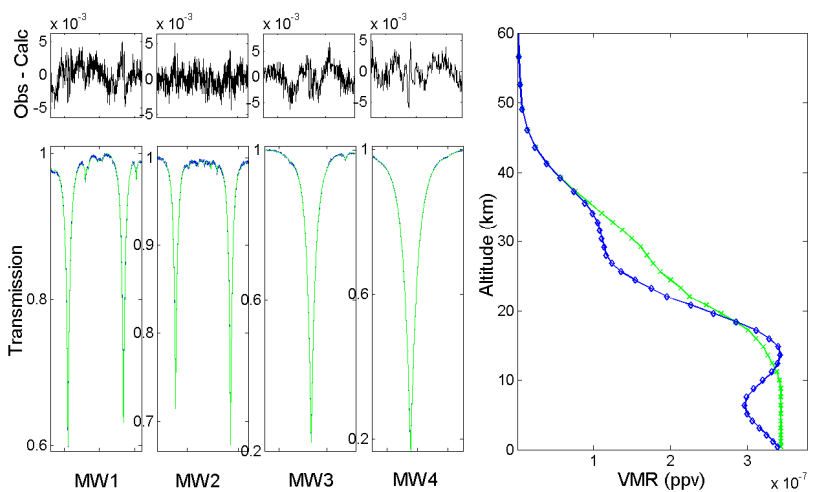

(b)
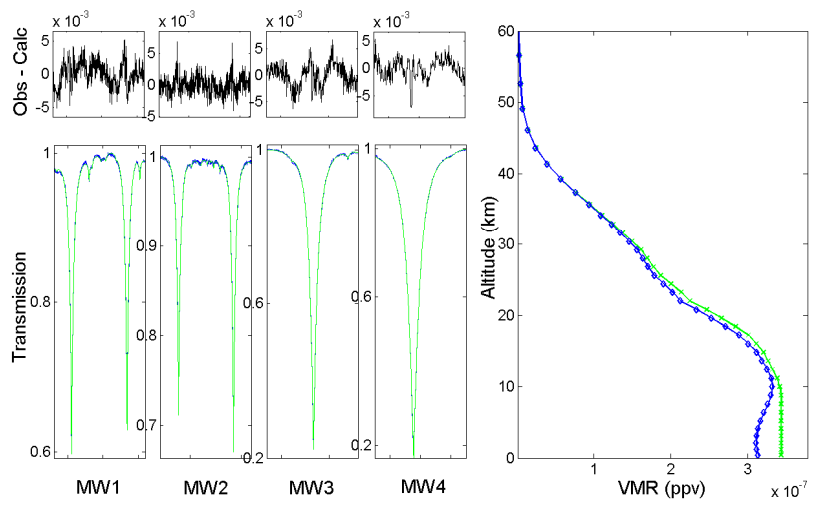

(c)
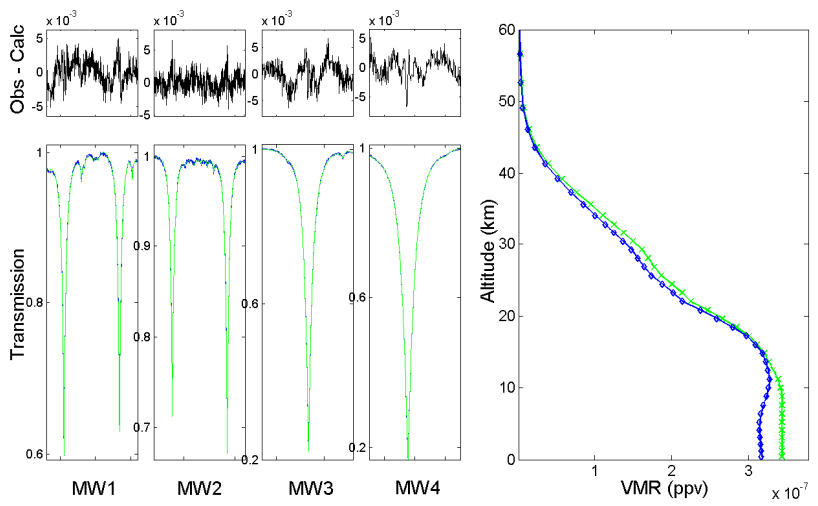

Fig. 5. Multiple micro-window (MW1: 2481.30-2482.60, MW2: 2526.40-2528.20, MW3: 2537.85-2538.80, and MW4: $2540.10-2540.70 \mathrm{~cm}^{-1}$ ) fit of $\mathrm{N}_{2} \mathrm{O}$ plus interfering species from a single spectrum on 8 October 2007 at St.-Denis using the (a) OEM, (b) IOA and (c) TR. Measured (blue) and simulated (green) spectra are shown (left lower plot), together with the residuals (left upper plot), computed as measured minus simulated. The right plot shows the a priori (green crosses) and retrieved (blue diamonds) profile. 
Table 3. Date, OBP and SZA of the reference spectra for $\mathrm{O}_{3}, \mathrm{~N}_{2} \mathrm{O}, \mathrm{CH}_{4}$ and $\mathrm{CO}$ measured at Ile de La Réunion in 2007, together with the RMS of the fit residual, DOFS and independent PC limits when using the OEM, IOA and TR.

\begin{tabular}{|c|c|c|c|c|c|c|c|}
\hline Molec. & Date & $\mathrm{OBP}\left[\mathrm{cm}^{-1}\right]$ & SZA & Meth. & RMS & DOFS & PC limits $[\mathrm{km}]$ \\
\hline \multirow{3}{*}{$\mathrm{O}_{3}$} & \multirow{3}{*}{12 September } & \multirow{3}{*}{$600-1400$} & \multirow{3}{*}{51.83} & OEM & 1.01 & 4.68 & $0.05-7.0-19.0-26.2-100$ \\
\hline & & & & IOA & 1.02 & 3.92 & $0.05-9.4-21.4-29.8-100$ \\
\hline & & & & TR & 1.01 & 4.64 & $0.05-7.0-19.0-27.4-100$ \\
\hline \multirow{3}{*}{$\mathrm{N}_{2} \mathrm{O}$} & \multirow{3}{*}{8 October } & \multirow{3}{*}{$2400-3310$} & \multirow{3}{*}{42.03} & OEM & 0.18 & 3.35 & $0.05-4.6-13.0-100$ \\
\hline & & & & IOA & 0.19 & 2.87 & $0.05-5.8-15.4-100$ \\
\hline & & & & $\mathrm{TR}$ & 0.18 & 2.91 & $0.05-5.8-15.4-100$ \\
\hline \multirow{3}{*}{$\mathrm{CH}_{4}$} & \multirow{3}{*}{2 October } & \multirow{3}{*}{$2400-3310$} & \multirow{3}{*}{46.43} & OEM & 0.29 & 2.32 & $0.05-8.2-100$ \\
\hline & & & & IOA & 0.30 & 2.06 & $0.05-9.4-100$ \\
\hline & & & & TR & 0.30 & 2.29 & $0.05-9.4-100$ \\
\hline \multirow{3}{*}{$\mathrm{CO}$} & \multirow{3}{*}{29 July } & \multirow{3}{*}{$1850-2750$} & \multirow{3}{*}{42.19} & OEM & 0.39 & 3.04 & $0.05-2.6-9.4-100$ \\
\hline & & & & IOA & 0.39 & 2.81 & $0.05-2.6-9.4-100$ \\
\hline & & & & TR & 0.39 & 3.09 & $0.05-2.6-9.4-100$ \\
\hline
\end{tabular}

Table 4. Mean RMS of the fit residual, mean ITER, mean DOFS, total altitude range and common independent PC ranges, mean CA, and mean daily relative STD on the CA for the retrievals of $\mathrm{O}_{3}, \mathrm{~N}_{2} \mathrm{O}, \mathrm{CH}_{4}$ and $\mathrm{CO}$, from the 2007 campaign data at Ile de La Réunion, when using the OEM, IOA and TR.

\begin{tabular}{|c|c|c|c|c|c|c|}
\hline Molec. & $\begin{array}{r}\text { RMS } \\
\text { OEM / IOA / TR }\end{array}$ & $\begin{array}{r}\text { ITER } \\
\text { OEM / IOA / TR }\end{array}$ & $\begin{array}{r}\text { DOFS } \\
\text { OEM / IOA / TR }\end{array}$ & Alt. range $[\mathrm{km}]$ & $\begin{array}{r}\mathrm{CA}\left[10^{18} \mathrm{molec} \mathrm{cm}^{-2}\right] \\
\mathrm{OEM} / \mathrm{IOA} / \mathrm{TR}\end{array}$ & $\begin{array}{r}\text { STD [\%] } \\
\text { OEM / IOA / TR }\end{array}$ \\
\hline $\mathrm{O}_{3}$ & $0.86 / 0.87 / 0.86$ & $7 / 7 / 7$ & $4.6 / 3.9 / 4.6$ & $\begin{array}{r}0.05-100 \\
0.05-9.4 \\
9.4-21.4 \\
21.4-29.8 \\
29.8-100\end{array}$ & $\begin{array}{l}7.90 / 7.90 / 7.90 \\
0.74 / 0.72 / 0.74 \\
1.33 / 1.32 / 1.34 \\
3.84 / 3.87 / 3.83 \\
1.99 / 1.98 / 1.99\end{array}$ & $\begin{array}{l}0.32 / 0.35 / 0.31 \\
0.90 / 0.99 / 0.89 \\
0.98 / 1.38 / 0.99 \\
0.57 / 0.61 / 0.54 \\
0.88 / 1.02 / 0.74\end{array}$ \\
\hline $\mathrm{N}_{2} \mathrm{O}$ & $0.15 / 0.15 / 0.15$ & $9 / 5 / 5$ & $3.1 / 2.9 / 2.9$ & $\begin{array}{r}0.05-100 \\
0.05-5.8 \\
5.8-15.4 \\
15.4-100\end{array}$ & $\begin{array}{l}6.67 / 6.66 / 6.66 \\
3.48 \text { / } 3.43 \text { / } 3.44 \\
2.54 / 2.59 \text { / } 2.58 \\
0.64 / 0.64 / 0.64\end{array}$ & $\begin{array}{r}0.060 / 0.058 / 0.053 \\
0.29 / 0.16 / 0.16 \\
0.37 / 0.19 / 0.17 \\
0.53 / 0.24 / 0.29\end{array}$ \\
\hline $\mathrm{CH}_{4}$ & $0.29 / 0.28 / 0.28$ & $9 / 6 / 6$ & $2.2 / 2.1 / 2.3$ & $\begin{array}{r}0.05-100 \\
0.05-9.4 \\
9.4-100\end{array}$ & $\begin{array}{l}36.5 / 37.1 / 36.9 \\
25.1 / 25.8 / 25.5 \\
11.4 / 11.3 / 11.4\end{array}$ & $\begin{array}{l}0.48 / 0.29 / 0.22 \\
0.41 / 0.72 / 0.30 \\
1.01 / 0.73 / 0.28\end{array}$ \\
\hline $\mathrm{CO}$ & $0.44 / 0.45 / 0.44$ & $7 / 7 / 7$ & $3.1 / 2.8 / 3.0$ & $\begin{array}{r}0.05-100 \\
0.05-2.6 \\
2.6-9.4 \\
9.4-100\end{array}$ & $\begin{array}{l}1.67 / 1.67 / 1.66 \\
0.51 / 0.49 / 0.49 \\
0.72 / 0.75 / 0.76 \\
0.44 / 0.43 / 0.40\end{array}$ & $\begin{array}{l}0.73 / 0.75 / 0.73 \\
2.39 / 2.45 / 2.00 \\
2.42 / 2.13 / 1.47 \\
1.66 / 1.71 / 1.23\end{array}$ \\
\hline
\end{tabular}

It is obvious that this "eigenvector approach" uses a priori information in the same statistical sense as the original optimal estimation method. Though, it has the advantage that only those components are considered about which the measurement actually provides information. In addition, since basically only a linear combination of the significant eigenvectors has to be calculated and since the $\mathrm{QR}$ method is very efficient and numerically stable, the IOA is expected to encounter fewer singularity problems than the OEM and TR.

\subsubsection{Information content and sensitivity}

The retrieved state vector $\boldsymbol{x}_{\mathrm{r}}$ is related to the a priori and the true state vectors $\boldsymbol{x}_{\mathrm{a}}$ and $\boldsymbol{x}$, respectively, by the equation (Rodgers, 2000):

$\boldsymbol{x}_{\mathrm{r}}=\mathbf{x}_{\mathrm{a}}+\mathbf{A}\left(\mathbf{x}-\mathbf{x}_{\mathrm{a}}\right)$,

where $\mathbf{A}$ is defined as $\delta \boldsymbol{x}_{\mathrm{r}} / \delta \boldsymbol{x}$, or in the case of OEM:

$$
\mathbf{A}=\left(\mathbf{K}_{\mathrm{r}}^{\mathrm{T}} \mathbf{S}_{y}^{-1} \mathbf{K}_{\mathrm{r}}+\mathbf{S}_{\mathrm{a}}^{-1}\right)^{-1} \mathbf{K}_{\mathrm{r}}^{\mathrm{T}} \mathbf{S}_{y}^{-1} \mathbf{K}_{\mathrm{r}}
$$


(a)

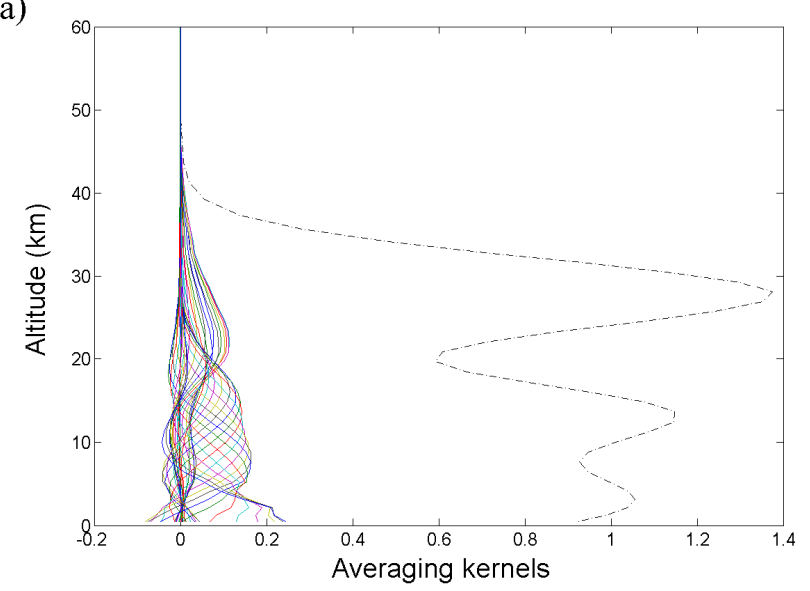

(b)

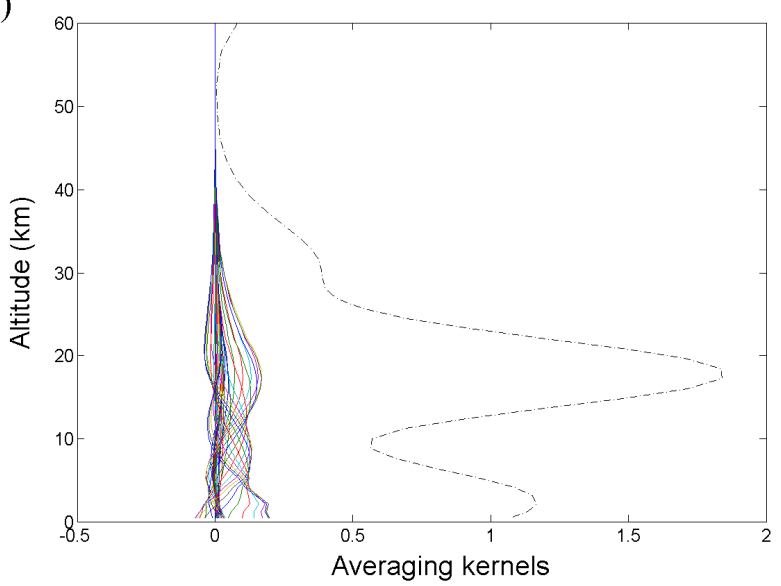

(c)

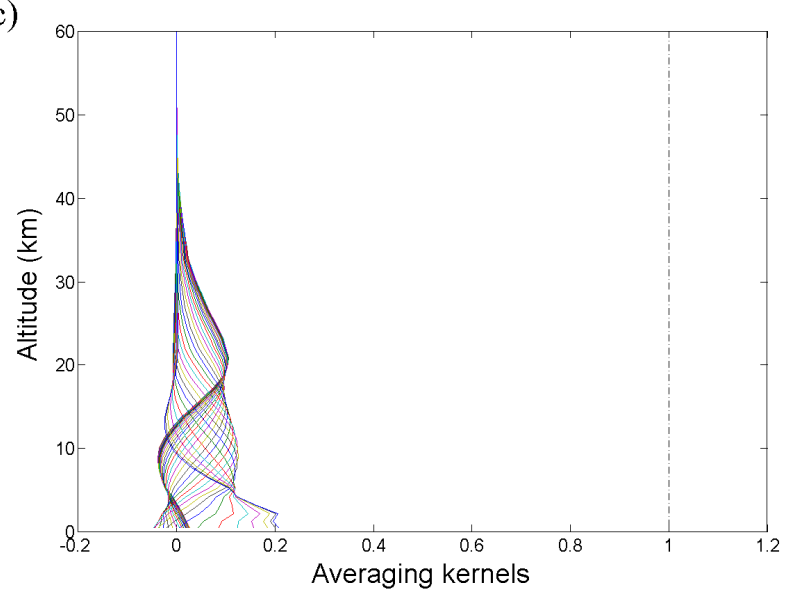

Fig. 6. Averaging kernels and sensitivity curve (black dashed) for the $\mathrm{N}_{2} \mathrm{O}$ retrieval from a single spectrum on 8 October 2007 at St.Denis using the (a) OEM, (b) IOA and (c) TR. (a)
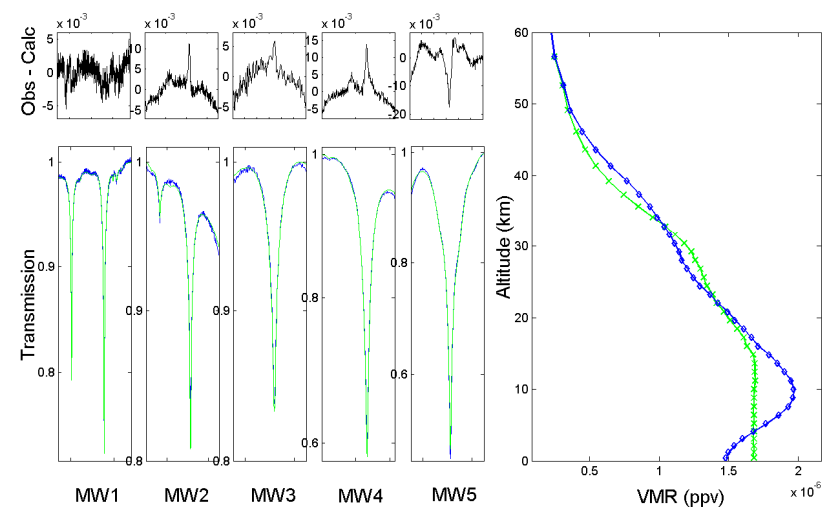

(b)
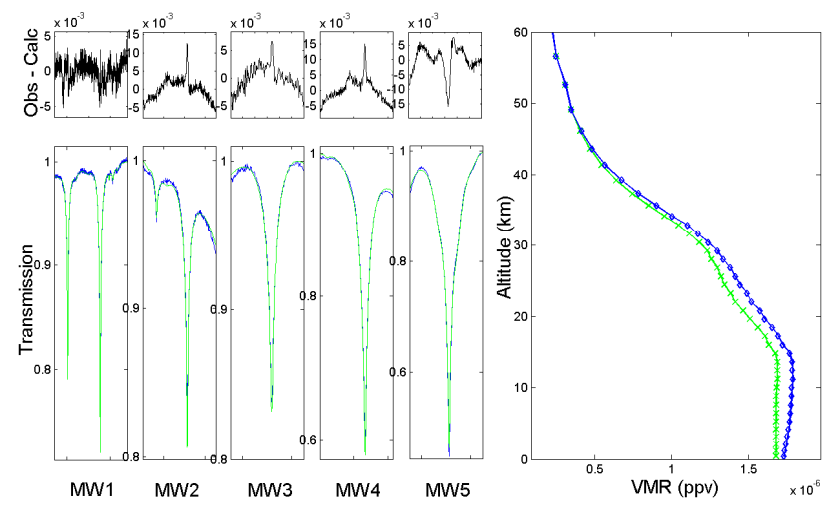

(c)
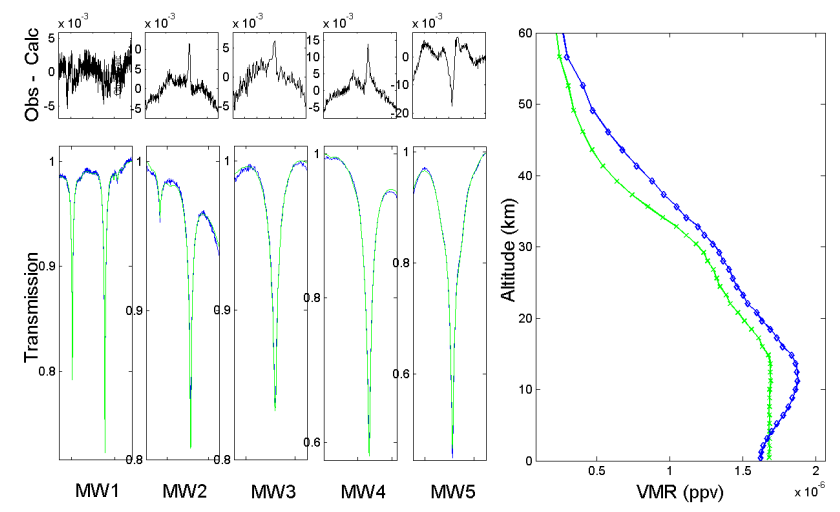

Fig. 7. Multiple micro-window (MW1: 2613.70-2615.40, MW2: 2650.60-2651.30, MW3: 2835.50-2835.80, MW4: 2903.602904.03, and MW5: $2921.00-2921.60 \mathrm{~cm}^{-1}$ ) fit of $\mathrm{CH}_{4}$ plus interfering species from a single spectrum on 2 October 2007 at St.Denis using the (a) OEM, (b) IOA and (c) TR. Measured (blue) and simulated (green) spectra are shown (left lower plot), together with the residuals (left upper plot), computed as measured minus simulated. The right plot shows the a priori (green crosses) and retrieved (blue diamonds) profile. 
(a)

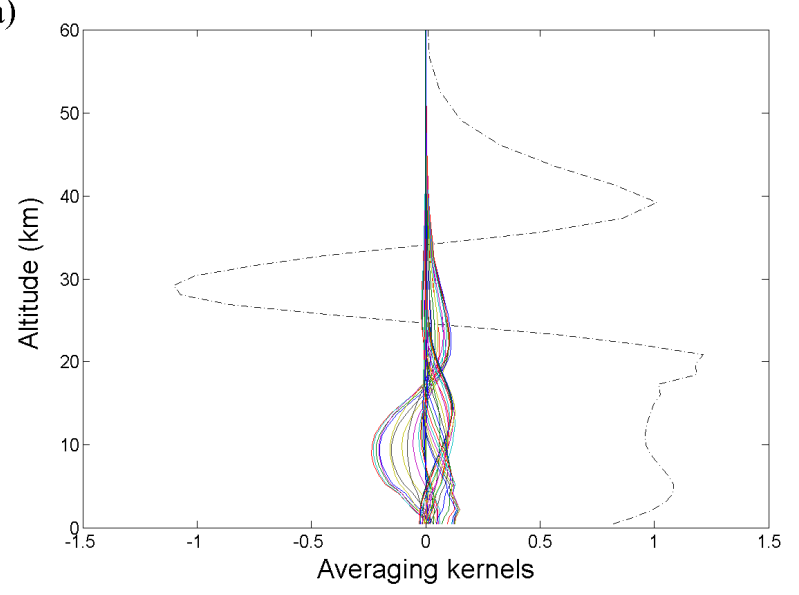

(b)

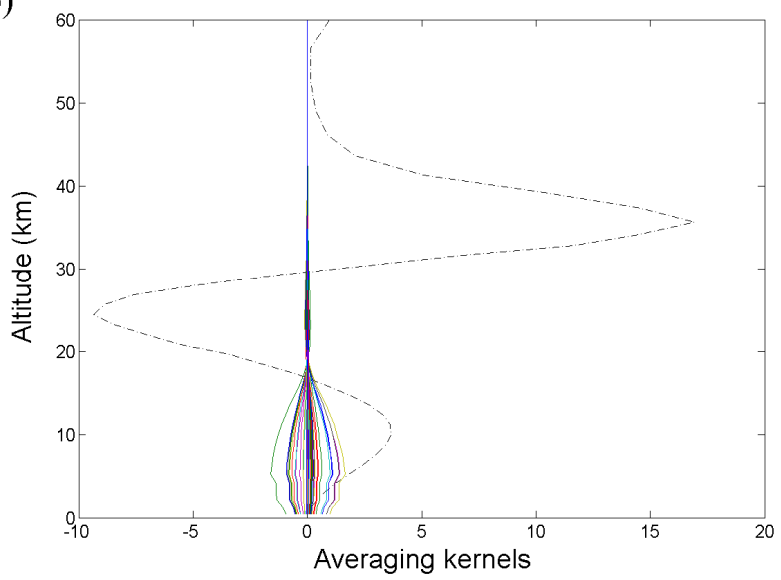

(c)

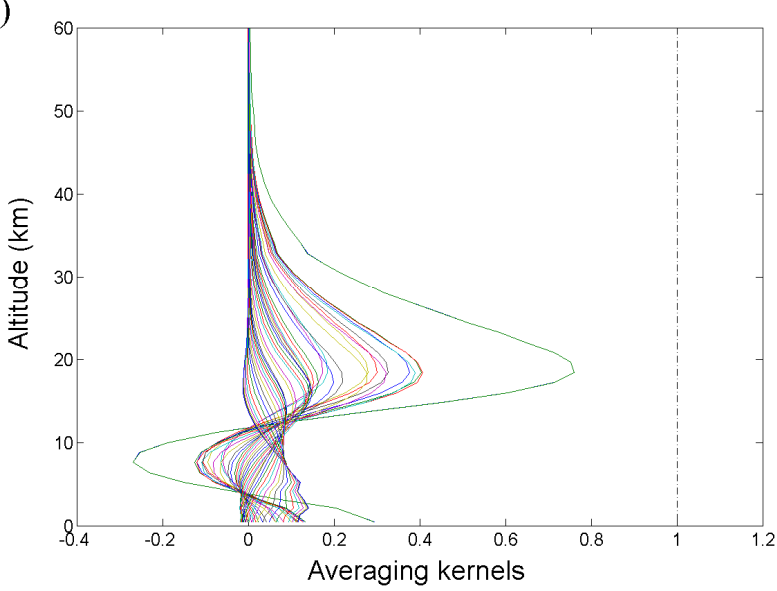

Fig. 8. Averaging kernels and sensitivity curve (black dashed) for the $\mathrm{CH}_{4}$ retrieval from a single spectrum on 2 October 2007 at St.Denis using the (a) OEM, (b) IOA and (c) TR. (a)
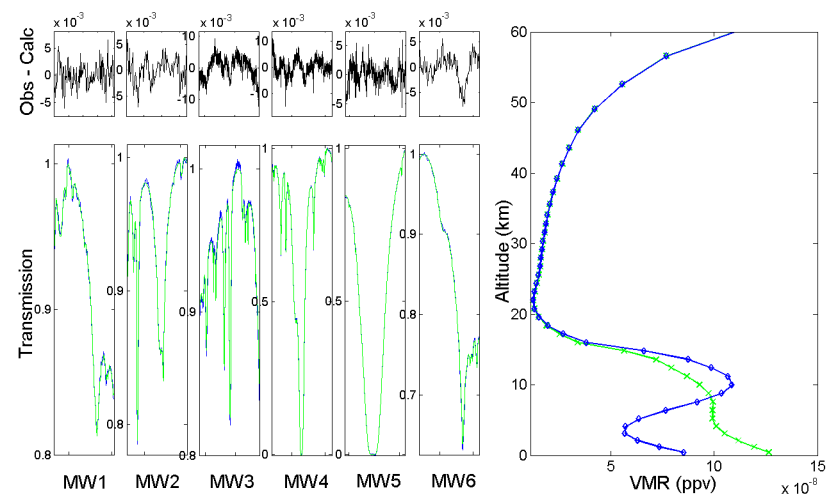

(b)
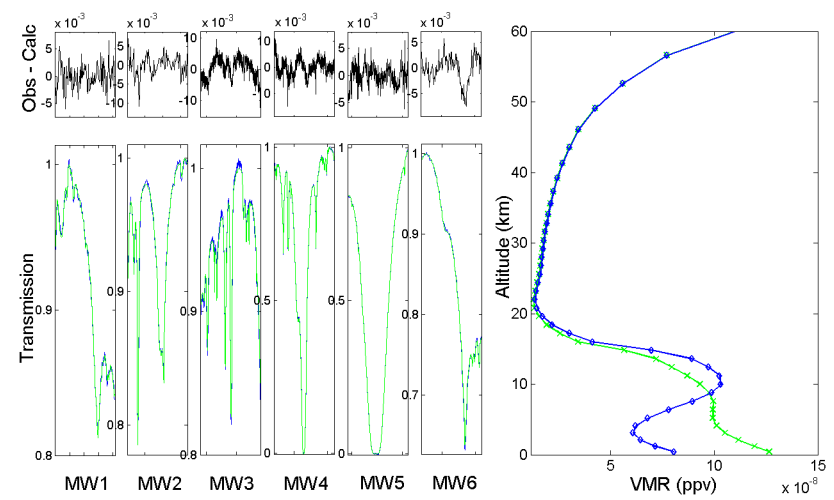

(c)
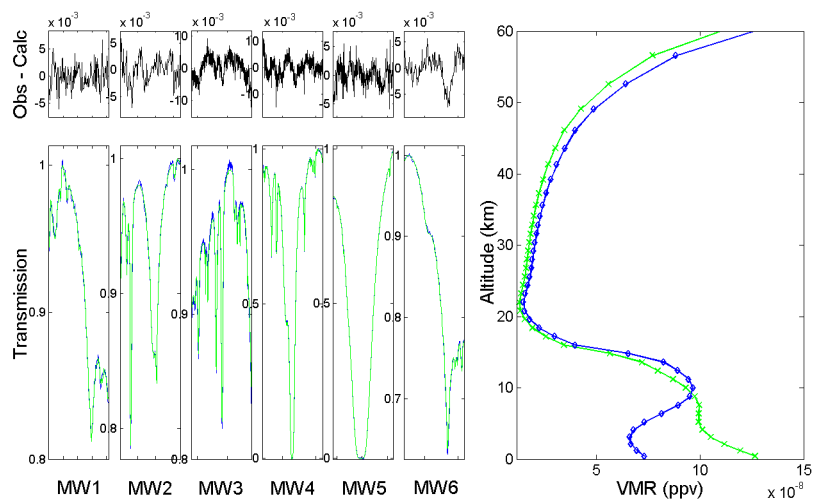

Fig. 9. Multiple micro-window (MW1: 2057.702057.91, MW2: 2069.55-2069.72, MW3: 2140.40-2141.40, MW4: 2157.40-2159.20, MW5: 2165.37-2165.85, and MW6: 2168.84-2169.02 $\mathrm{cm}^{-1}$ ) fit of CO plus interfering species from a single spectrum on 29 July 2007 at St.-Denis using the (a) OEM, (b) IOA and (c) TR. Measured (blue) and simulated (green) spectra are shown (left lower plot), together with the residuals (left upper plot), computed as measured minus simulated. The right plot shows the a priori (green crosses) and retrieved (blue diamonds) profile. 
(a)

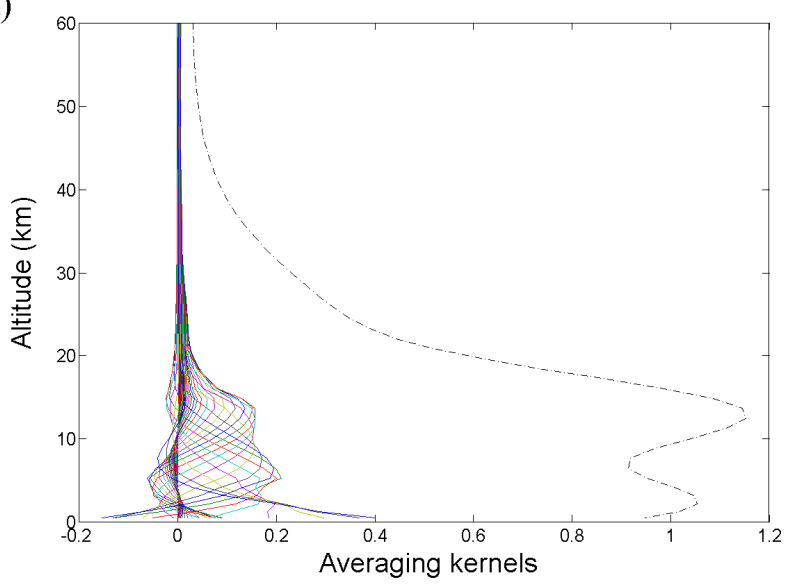

(b)

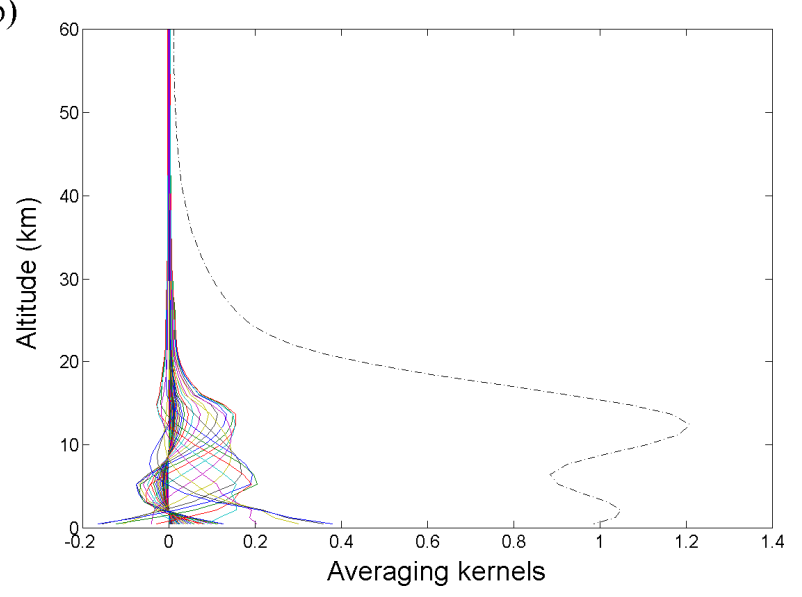

(c)

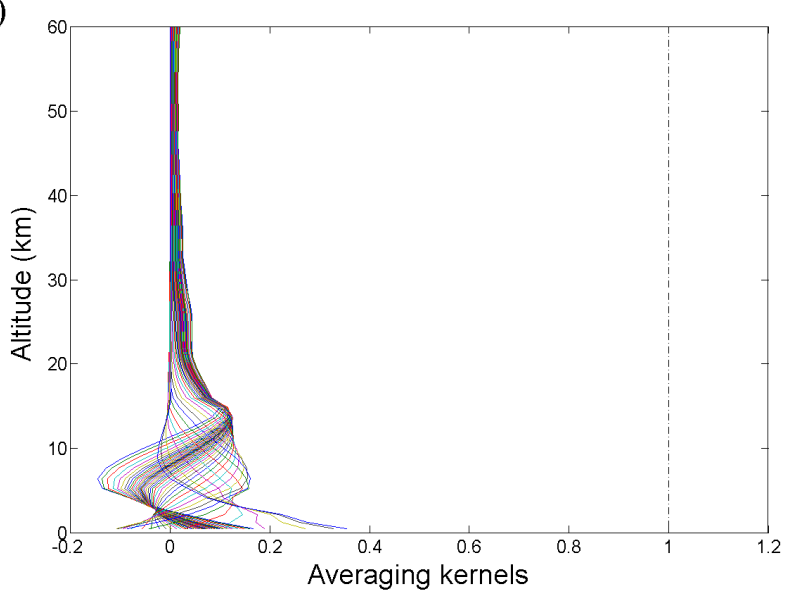

Fig. 10. Averaging kernels and sensitivity curve (black dashed) for the CO retrieval from a single spectrum on 29 July 2007 at St.-Denis using the (a) OEM, (b) IOA and (c) TR. (a)

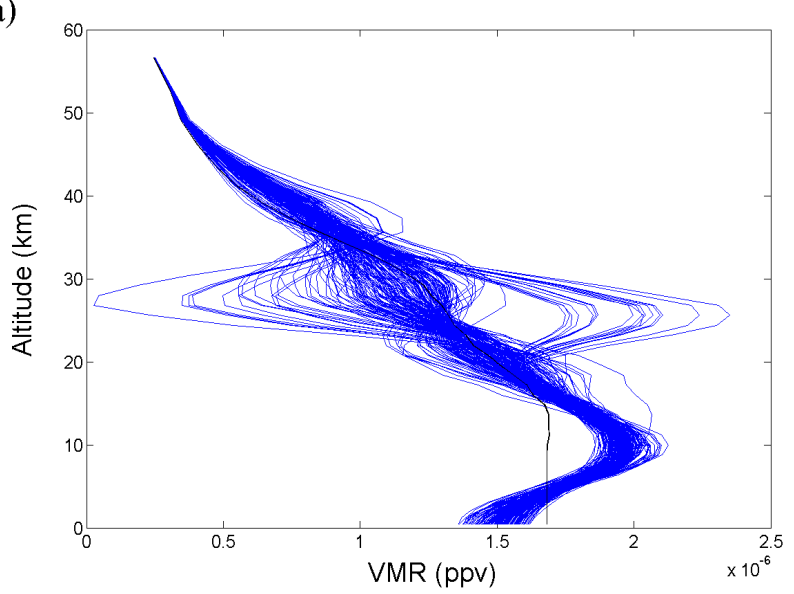

(b)

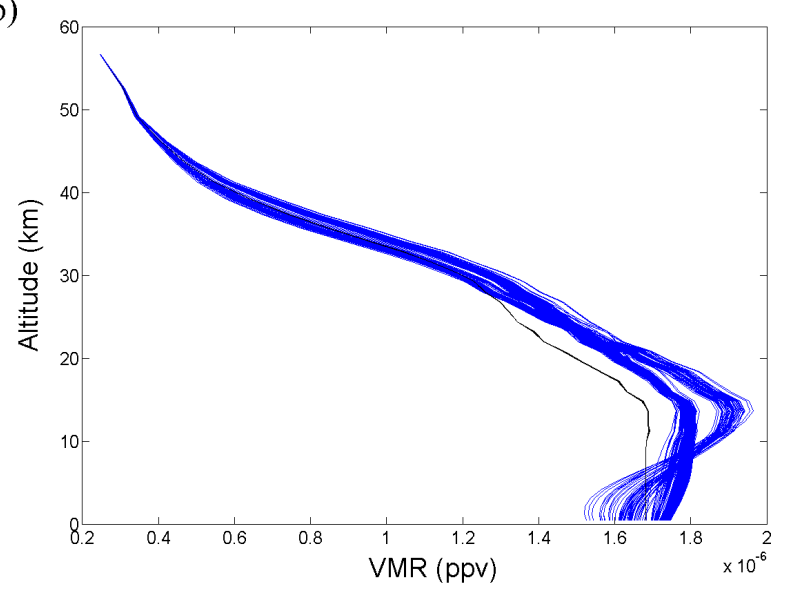

(c)

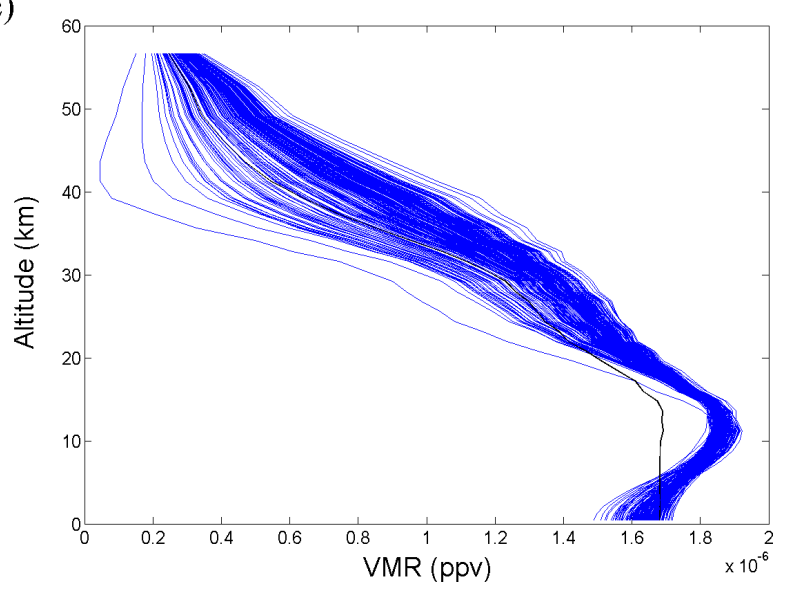

Fig. 11. $\mathrm{CH}_{4}$ profiles from all spectra taken at St.-Denis during the 2007 campaign, retrieved with the (a) OEM, (b) IOA and (c) TR, respectively. The black line corresponds to the a priori profile used. 
The rows of the matrix $\mathbf{A}$ are called the averaging kernels, and the trace of $\mathbf{A}$ equals the number of degrees of freedom for signal (DOFS). Note that essentially the DOFS comprises two shares, namely one corresponding to the fitted VMR values of the target profile and one corresponding to the other fitted parameters within the state vector. In what follows the term DOFS will refer to the target part only, unless stated otherwise.

For each of the retrieval layers the full width at half maximum of the averaging kernel provides an estimate of the vertical resolution of the profile retrieval at the corresponding altitude, while the area of the averaging kernel (i.e. the sum of its elements) represents the sensitivity of the retrieval at the corresponding altitude to the true state. The DOFS together with the averaging kernel shapes define the independent partial columns that best represent the retrieval results.

The matrix $\mathbf{A}$ in Eq. (8) can be written as a function of $\mathbf{P}_{\mathrm{r}}$, namely:

$\mathbf{A}=\left(\mathbf{S}_{\mathrm{a}} \mathbf{K}_{\mathrm{r}}^{\mathrm{T}} \mathbf{S}_{y}^{-1} \mathbf{K}_{\mathrm{r}}+\mathbf{I}\right)^{-1} \mathbf{S}_{\mathrm{a}} \mathbf{K}_{\mathrm{r}}^{\mathrm{T}} \mathbf{S}_{y}^{-1} \mathbf{K}_{\mathrm{r}}=\left(\mathbf{P}_{\mathrm{r}}+\mathbf{I}\right)^{-1} \mathbf{P}_{\mathrm{r}}$,

such that the trace of $\mathbf{A}$ equals $\sum_{n=1}^{N} \quad \lambda_{\mathrm{r}, n} /\left(1+\lambda_{\mathrm{r}, n}\right)$ in the case of OEM.

When we derive $\mathbf{A}$ in the case of IOA, we get the following expression for each element $i, j$ of $\mathbf{A}(i=1, \ldots, N$ and $j=$ $1, \ldots, N)$ :

$$
\begin{aligned}
(\mathbf{A})_{i, j}= & \sum_{n=1}^{N_{\mathrm{opt}}} \lambda_{\mathrm{r}, n} /\left[N_{r, n}\left(1+\lambda_{\mathrm{r}, n}\right)\right] \\
& \left(\boldsymbol{\phi}_{\mathrm{r}, n}^{\mathrm{T}} \mathbf{K}_{\mathrm{r}}^{\mathrm{T}} \mathbf{S}_{y}^{-1} \mathbf{K}_{\mathrm{r}}\right)_{1, j}\left(\boldsymbol{\phi}_{\mathrm{r}, n}\right)_{i, 1} .
\end{aligned}
$$

The trace of $\mathbf{A}$, or the total DOFS, now equals $\sum_{n=1}^{N_{\mathrm{opt}}} \lambda_{\mathrm{r}, n}$ $/\left(1+\lambda_{\mathrm{r}, n}\right)$. Note that if we would use all eigenvalues of $\mathbf{P}_{\text {r }}$ (i.e. $\left.N_{\text {opt }}=N\right)$, instead of only the significant ones, this would correspond to the trace of $\mathbf{A}$ resulting from the OEM.

Analogous to $\mathbf{A}$, in the case of IOA, the gain matrix $\mathbf{G}_{\mathrm{r}}$, defined as $\delta \boldsymbol{x}_{\mathrm{r}} / \delta \boldsymbol{y}$, becomes:

$$
\begin{aligned}
\left(\mathbf{G}_{\mathrm{r}}\right)_{i, j}= & \sum_{n=1}^{N_{\mathrm{opt}}} \lambda_{\mathrm{r}, n} /\left[N_{\mathrm{r}, n}\left(1+\lambda_{\mathrm{r}, n}\right)\right] \\
& \left(\boldsymbol{\phi}_{\mathrm{r}, n}^{\mathrm{T}} \mathbf{K}_{\mathrm{r}}^{\mathrm{T}} \mathbf{S}_{y}^{-1}\right)_{1, j}\left(\boldsymbol{\phi}_{\mathrm{r}, n}\right)_{i, 1},
\end{aligned}
$$

with $i=1, \ldots, N$ and $j=1, \ldots, M$.

Note that all definitions of the error components for the OEM are still valid for the IOA applied onto the OEM, as this alternative retrieval method is based on the same premises. In the numerical evaluations we have to use the adapted expressions for the averaging kernel and gain matrix (Eqs. 10 and 11).

\subsubsection{Tikhonov regularization}

Besides the OEM, Tikhonov regularization (TR) is another commonly used method for the retrieval of the vertical distribution of trace gases from FTIR absorption spectra. The TR solution is calculated iteratively by the following expression (Schimpf and Schreier, 1997):

$$
\begin{aligned}
\boldsymbol{x}_{i+1} & =\boldsymbol{x}_{\mathrm{a}}+\left(\mathbf{K}_{i}^{\mathrm{T}} \mathbf{S}_{y}^{-1} \mathbf{K}_{i}+\alpha \mathbf{R}^{\mathrm{T}} \mathbf{R}\right)^{-1} \mathbf{K}_{i}^{\mathrm{T}} \mathbf{S}_{y}^{-1}\left[\boldsymbol{y}-\boldsymbol{y}_{i}\right. \\
& \left.+\mathbf{K}_{i}\left(\boldsymbol{x}_{i}-\boldsymbol{x}_{\mathrm{a}}\right)\right],
\end{aligned}
$$

where $\mathbf{R}$ and $\alpha$ are the regularization matrix and regularization parameter, respectively. Both are introduced to constrain the state vector or, in other words, to incorporate information about the solution magnitude and smoothness. Again, all error components are calculated in the same way as for the OEM retrievals.

For the retrievals obtained with TR, we have used the $\mathbf{L}_{1}$ regularization matrix, i.e. $\mathbf{R}=\mathbf{L}_{1}$. This $\mathbf{L}_{1}$ is by definition a $(N-1) \times N$ matrix composed by zeros except for the elements $\mathbf{L}_{1}(\mathrm{i}, \mathrm{i})=-1$ and $\mathbf{L}_{1}(i, i+1)=1$, for $i=1, \ldots, N-1$. For this particular choice of $\mathbf{R}$ the averaging kernel matrix $\mathbf{A}$ becomes:

$\mathbf{A}=\left(\mathbf{K}_{\mathrm{r}}^{\mathrm{T}} \mathbf{S}_{y}^{-1} \mathbf{K}_{\mathrm{r}}+\alpha \mathbf{L}_{1}^{\mathrm{T}} \mathbf{L}_{1}\right)^{-1} \mathbf{K}_{\mathrm{r}}^{\mathrm{T}} \mathbf{S}_{y}^{-1} \mathbf{K}_{\mathrm{r}}$.

Consequently, the sum of all elements of each row of $\mathbf{A}$ equals 1 , as can be seen from a simple matrix manipulation. This is valid for each choice of $\alpha$. In other words, for the Tikhonov retrievals in this paper the sensitivity is always 1 at every altitude and is not a relevant parameter.

The parameter $\alpha$ we have used is the one that results in the best compromise between the DOFS and the total random error on the retrieved total column. Note that this total random error we have evaluated here by summing up the covariance matrices of the forward model parameter error, the smoothing error, the interfering species' errors and the measurement noise error, assuming that the other error components do not vary with $\alpha$. This tuning method is based on the discussion in Steck (2002) showing that the DOFS as well as the total random error decreases with increasing $\alpha$.

\section{Application of the IOA to ground-based FTIR data}

As discussed in the introduction, we have focused on the retrieval results of $\mathrm{O}_{3}, \mathrm{~N}_{2} \mathrm{O}, \mathrm{CH}_{4}$ and $\mathrm{CO}$. In addition to the total column abundances of these molecules, we have extracted information - whenever feasible - about their vertical distribution between the ground and $100 \mathrm{~km}$ altitude. In this section we give an overview of the measurement characteristics, the retrieval strategy used, and the OEM, IOA and TR retrieval results, including mutual comparisons.

\subsection{Specifications of the FTIR measurements}

Before continuous operations started in May 2009, three FTIR solar absorption measurement campaigns had been carried out at Ile de La Réunion, namely in 2002, 2004 and 2007. Within the scope of this paper we concentrate on 
Table 5. Smoothing error, total random error without the smoothing error contribution, total random error, total systematic error and total error on the retrieved total and partial columns of $\mathrm{O}_{3}, \mathrm{~N}_{2} \mathrm{O}, \mathrm{CH}_{4}$ and $\mathrm{CO}$, at Ile de La Réunion in 2007, when using the OEM, IOA and TR.

\begin{tabular}{|c|c|c|c|c|c|c|}
\hline Molec. & $\begin{array}{r}\text { Alt. range } \\
{[\mathrm{km}]}\end{array}$ & $\begin{array}{l}\text { Smoothing [\%] } \\
\text { OEM / IOA / TR }\end{array}$ & $\begin{array}{r}\text { Total rand. without } \\
\text { smoothing error [\%] } \\
\text { OEM / IOA / TR }\end{array}$ & $\begin{array}{l}\text { Total rand. [\%] } \\
\text { OEM / IOA / TR }\end{array}$ & $\begin{array}{l}\text { Total syst. [\%] } \\
\text { OEM / IOA / TR }\end{array}$ & $\begin{array}{r}\text { Total [\%] } \\
\text { OEM / IOA / TR }\end{array}$ \\
\hline \multirow{5}{*}{$\mathrm{O}_{3}$} & $0.05-100$ & $0.44 / 0.54 / 0.51$ & $0.80 / 0.62 / 0.81$ & $0.91 / 0.83 / 0.96$ & $2.54 / 1.71 / 2.84$ & $2.70 / 1.90 / 3.00$ \\
\hline & $0.05-9.4$ & $6.70 / 9.06 / 7.14$ & $1.62 / 1.39 / 1.55$ & $6.90 / 9.17 / 7.30$ & $14.32 / 12.48 / 14.18$ & $15.89 / 15.49 / 15.94$ \\
\hline & $9.4-21.4$ & $9.05 / 10.71 / 10.31$ & $3.35 / 2.26 / 2.91$ & $9.65 / 10.94 / 10.71$ & $27.20 / 13.76 / 23.77$ & $28.86 / 17.58 / 26.07$ \\
\hline & $21.4-29.8$ & $5.56 / 7.58 / 6.70$ & $3.12 / 1.75 / 2.52$ & $6.38 / 7.78 / 7.16$ & $21.89 / 7.84 / 17.41$ & $22.80 / 11.05 / 18.82$ \\
\hline & $29.8-100$ & 5.03 / 6.57 / 6.34 & $2.48 / 2.03 / 2.02$ & $5.61 / 6.88 / 6.65$ & $13.83 / 7.75 / 9.75$ & $14.93 / 10.36 / 11.81$ \\
\hline \multirow{4}{*}{$\mathrm{N}_{2} \mathrm{O}$} & $0.05-100$ & $0.10 / 0.27 / 0.073$ & $0.49 / 0.35 / 0.33$ & $0.50 / 0.44 / 0.34$ & $2.49 / 2.64 / 2.68$ & $2.54 / 2.68 / 2.70$ \\
\hline & $0.05-5.8$ & $0.55 / 1.36 / 0.40$ & $1.05 / 0.64 / 0.64$ & $1.18 / 1.50 / 0.75$ & $5.41 / 4.77 / 4.68$ & $5.53 / 5.00 / 4.74$ \\
\hline & $5.8-15.4$ & $0.72 / 2.18 / 0.65$ & $1.33 / 0.56 / 0.49$ & $1.51 / 2.25 / 0.81$ & $5.26 / 5.11 / 5.07$ & $5.48 / 5.59 / 5.14$ \\
\hline & $15.4-100$ & $1.39 / 4.84 / 1.47$ & $2.85 / 1.51 / 1.07$ & 3.17 / 5.07 / 1.82 & $12.61 / 5.56 / 4.05$ & $13.00 / 7.53 / 4.44$ \\
\hline \multirow{3}{*}{$\mathrm{CH}_{4}$} & $0.05-100$ & $0.22 / 1.09 / 0.31$ & $0.95 / 0.97 / 0.93$ & 0.98 & $4.83 / 7.28 / 5.21$ & $4.93 / 7.42 / 5.30$ \\
\hline & $0.05-9.4$ & $0.41 / 2.29 / 0.64$ & $1.08 / 0.94 / 0.97$ & $1.16 / 2.48 / 1.16$ & $7.54 / 7.48 / 7.72$ & $7.63 / 7.88 / 7.81$ \\
\hline & $9.4-100$ & $0.60 / 2.91 / 0.61$ & $1.50 / 1.09 / 1.46$ & $1.61 / 3.10 / 1.59$ & 7.85 / 6.87 / 8.16 & $8.01 / 7.54 / 8.32$ \\
\hline \multirow{4}{*}{$\mathrm{CO}$} & $0.05-100$ & $0.15 / 0.15 / 0.37$ & $1.29 / 1.22 / 1.15$ & $1.30 / 1.23 / 1.21$ & $3.52 / 2.88 / 2.93$ & $3.75 / 3.13 / 3.17$ \\
\hline & $0.05-2.6$ & $1.92 / 2.45 / 3.94$ & $4.37 / 3.76 / 3.38$ & $4.78 / 4.49 / 5.19$ & $30.16 / 24.14 / 16.59$ & $30.54 / 24.56 / 17.39$ \\
\hline & $2.6-9.4$ & $2.22 / 2.67 / 4.16$ & $2.20 / 2.15 / 1.24$ & $3.13 / 3.43 / 4.34$ & $35.92 / 27.31 / 15.90$ & $36.05 / 27.53 / 16.48$ \\
\hline & $9.4-100$ & $2.18 / 2.47 / 4.94$ & $2.28 / 2.07 / 1.43$ & $3.16 / 3.23 / 5.14$ & 33.99 / 22.82 / 9.95 & $34.13 / 23.05 / 11.20$ \\
\hline
\end{tabular}

spectra taken during the third campaign, from May to October 2007. In particular, these spectra are recorded using a mobile Bruker $120 \mathrm{M}$ Fourier Transform spectrometer installed at the St.-Denis University campus $(50 \mathrm{~m}$ a.s.l., $20^{\circ} 54^{\prime} \mathrm{S}$ and $55^{\circ} 29^{\prime} \mathrm{E}$ ). The 2007 campaign was performed with the same experimental setup as the 2004 campaign, which is described in detail in Senten et al. (2008). Note that the FTIR experiment at Ile de La Réunion is qualified as an NDACC-compliant experiment, confirming that it satisfies all quality criteria imposed by the NDACC Infrared Working Group.

\subsection{Retrieval results}

\subsubsection{Retrieval strategy and spectral fits}

For all retrievals discussed in this paper the absorption line parameters were taken from the HITRAN 2008 spectral database (Rothman et al., 2009) in combination with available updates on the HITRAN website (http://www.hitran. com). The spectral micro-windows in which the absorption features of the target and interfering species are fitted, are selected such that they contain unsaturated well-isolated absorption features of the target species with a minimal number of interfering absorption lines, and such that the amount of information present in the spectra - represented by the DOFS - is maximized.

The a priori profile $\boldsymbol{x}_{\mathrm{a}}$ used and its associated covariance matrix $\mathbf{S}_{\mathrm{a}}$ should represent a good guess of the "true" state, in particular at those altitudes for which it is difficult to get information out of the measurements. Note that in order to compare the OEM and IOA retrievals, we use the same $\boldsymbol{x}_{\mathrm{a}}$ and $\mathbf{S}_{\mathrm{a}}$ for both methods, rather than imposing the same DOFS.

The diagonal elements of the measurement error covariance matrix are defined to be an estimate of the squared reciprocals of a representative signal-to-noise ratio (SNR). The off-diagonal elements are set to zero, which means that the measurement errors at different wavelengths are assumed to be uncorrelated.

For the $\mathrm{N}_{2} \mathrm{O}$ and $\mathrm{CH}_{4}$ retrievals the selected microwindows (fitted simultaneously), the associated interfering molecules, the used a priori profiles and the corresponding a priori covariance matrices are adopted from Senten et al. (2008). The $\mathrm{O}_{3}$ retrieval strategy is the one used by Vigouroux et al. (2008), and for CO we adopted the strategy from Duflot et al. (2010). An overview of these choices is provided in Table 1.

\subsubsection{Choice of eigenvalues and eigenvectors to be used}

Before discussing the IOA retrieval results, we clarify the criteria to determine the most appropriate number $N_{\text {opt }}(\leq N)$ of terms to be used in the IOA sum, i.e. Eq. (5), yielding the best compromise between the information content and the stability of the retrieval results. In particular, a suitable threshold $g$ has to be searched for, meeting the condition $\lambda_{\mathrm{r}, n} /(1+$ $\left.\lambda_{\mathrm{r}, n}\right) \geq g$, with $g<1$. As the eigenvectors corresponding to 
(a)

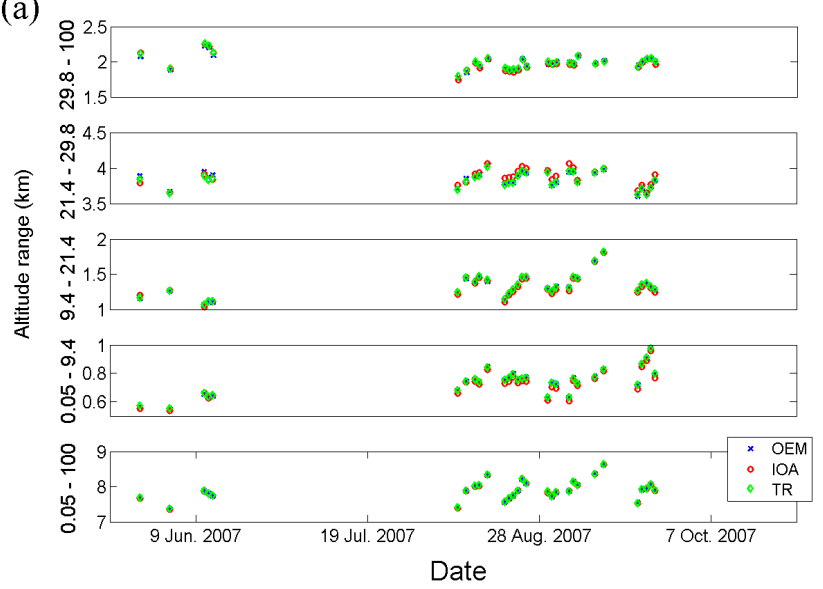

(c)
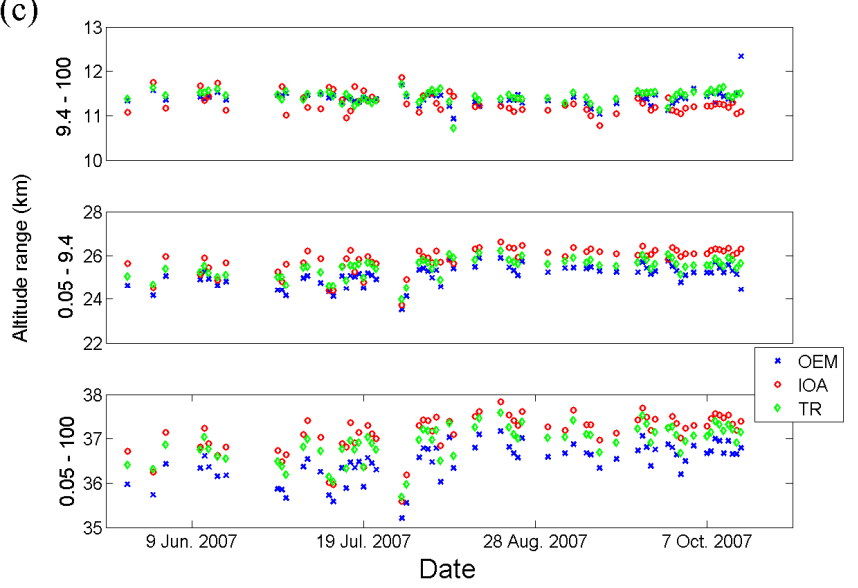

(b)

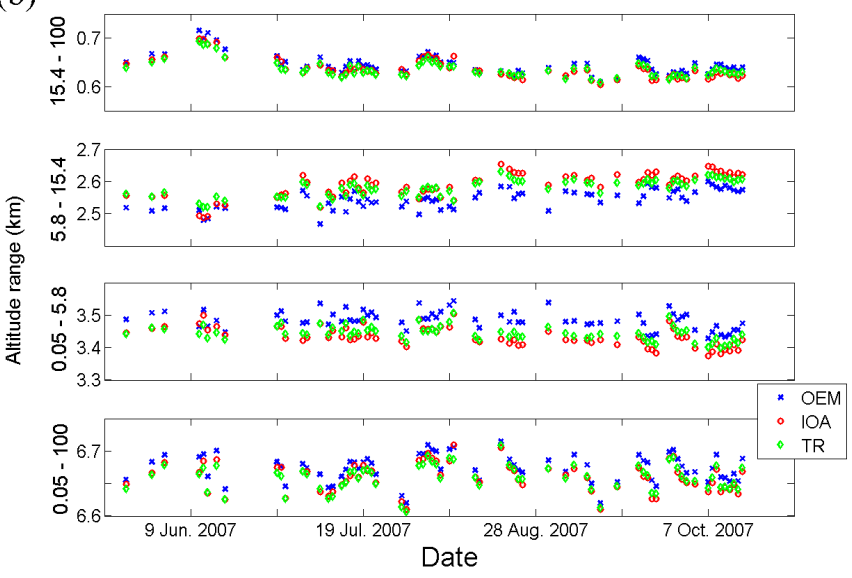

(d)
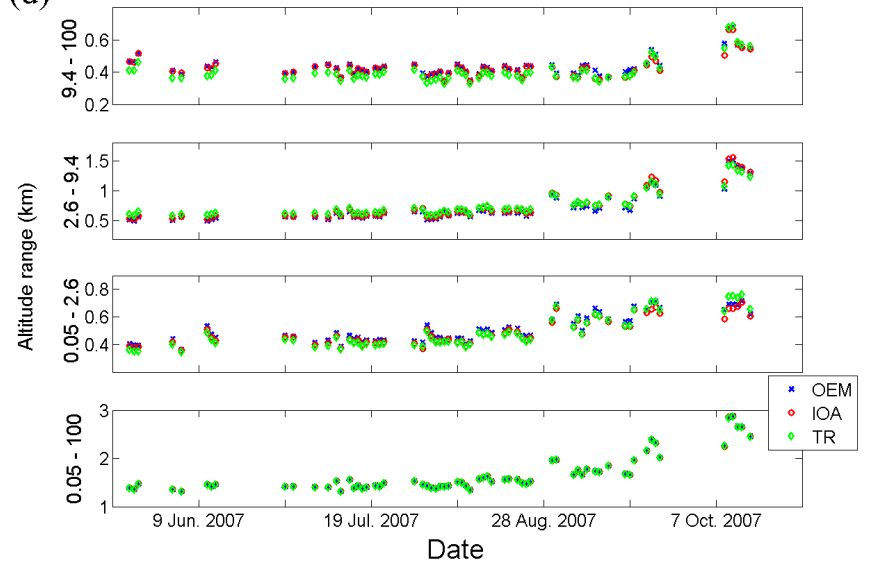

Fig. 12. Time series of the total and partial column amounts (in $10^{18}$ molec $\mathrm{cm}^{-2}$ ) of (a) $\mathrm{O}_{3}$, (b) $\mathrm{N}_{2} \mathrm{O},(\mathbf{c}) \mathrm{CH}_{4}$ and (d) $\mathrm{CO}$ during the FTIR campaign at St.-Denis in 2007, retrieved with the OEM (blue crosses), IOA (red circles) and TR (green diamonds), respectively.

smaller eigenvalues have the property of being more oscillatory, it is easy to understand that the more eigenvectors we include in the linear combination defining the retrieval solution, the more this solution will oscillate. On the other hand, if we do not include enough eigenvectors, the solution will no longer be representative of the true state and the DOFS will be considerably smaller. Table 2 shows the evolution of $1 / 2$ $\ln \left(\lambda_{\mathrm{r}, n}+1\right)$ and $\lambda_{\mathrm{r}, n} /\left(1+\lambda_{\mathrm{r}, n}\right)$ for the largest 24 eigenvalues $\lambda_{\mathrm{r}, n}$ of $\mathbf{P}_{\mathrm{r}}$ for an illustrative IOA retrieval of each target molecule. The systematic decrease of both quantities around 1 and 0.8 , respectively, indicates that including the subsequent smaller eigenvalues and eigenvectors in the IOA calculations would not significantly contribute to the solution. On the contrary, they would only induce unrealistic oscillations in the retrieved vertical profiles.

By definition of the IOA, when decreasing $g$, the IOA solution approaches the OEM solution, up to the point of using all eigenvalues and eigenvectors in the IOA sum, i.e. $g=0$, or equivalently, $N_{\mathrm{opt}}=N$ in Eq. (5). The remaining difference - though very small - between the retrieval result from the OEM and IOA with $g=0$ comes from the fact that the state space spanned by both methods is not exactly the same.

The impact of different threshold values between 0 and 1 on the retrieved profiles can be seen in Fig. 1, showing the $\mathrm{N}_{2} \mathrm{O}$ profiles for the whole 2007 campaign obtained with the OEM and with the IOA for $g$ equal to $0.09,0.79$ and 0.99 . These three values of $g$ correspond to including about 20, 17 and 15 terms in the IOA decomposition. These four approaches result in 3.1, 3.3, 2.9 and 1.6 DOFS on average, respectively. Consequently, the smoothing error increases. The root mean square (RMS) values of the spectral fit residual, calculated from the differences between the observed and simulated spectral points, equal $0.15,0.15,0.15$ and 0.16 on average, respectively. This demonstrates the poor sensitivity of the spectral fit to the choice of $g$, or correspondingly, to the retained dimension of the state space. Obviously, the IOA profiles for $g=0.99$ are less oscillatory than those for $g=0.79$, which in turn are less oscillating than those for $g=0.09$. These plots also confirm the statement that in the limit the IOA profiles move towards the OEM profiles. The 


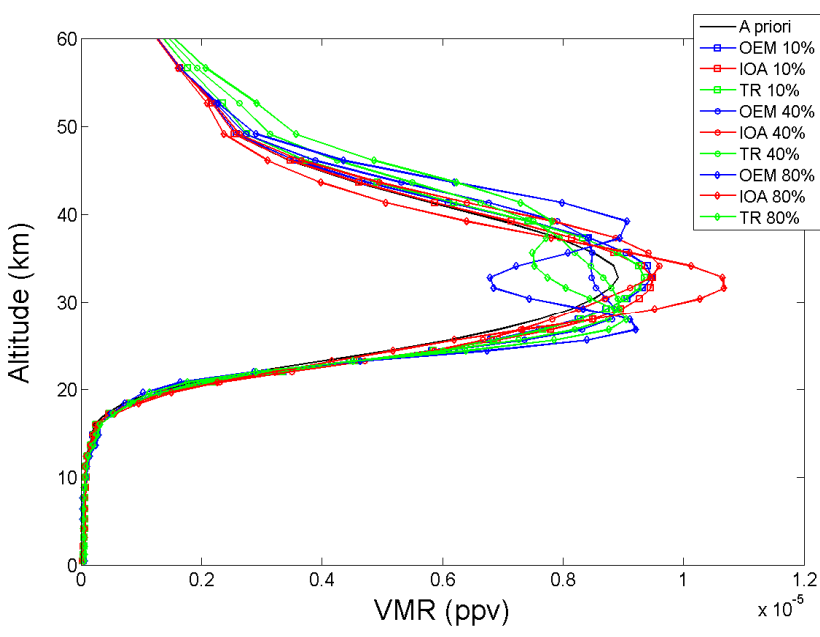

Fig. 13. $\mathrm{O}_{3}$ profile on 12 June 2007 at St.-Denis obtained when using $\mathbf{S}_{\mathrm{a}}$ with on its diagonal $10 \%$ (squares), $40 \%$ (circles) and $80 \%$ (diamonds), retrieved with the OEM (blue), IOA (red) and TR (green), respectively. The black profile is the unchanged a priori profile.

same behavior was observed in the tests we performed for the other target molecules.

Figure 2 shows the curves of $y=1 / 2 \ln (x+1)$ and $y=$ $x /(1+x)$ for $x$ between 0 and 20 and for the eigenvalues of the Kozlov information matrix $\mathbf{P}_{\mathrm{r}}$ that lay within this domain, for $\mathrm{O}_{3}$ and $\mathrm{CO}$. Clearly, the intersection point of these two curves is situated around 0.79 . Note that the eigenvalues of $\mathbf{P}_{\mathrm{r}}$ for $\mathrm{N}_{2} \mathrm{O}$ and $\mathrm{CH}_{4}$ yield similar graphs, but are left out here, just for clarity of the figure.

Based on the considerations above, we conclude that the best compromise is attained with the threshold $g=0.79$. This lower limit for the contribution to the information content of the measurement is valid for each target species and is used in all subsequent IOA retrievals discussed in this paper.

\subsubsection{Vertical profiles and column amounts}

For the discussion of the characteristics of the IOA compared to the OEM and TR, we analyzed the vertical profile and column retrievals for the complete set of 2007 spectra. However, full error budget evaluations are made here only for one reference spectrum for each target molecule, because performing the error calculations for all spectra would have been too time-consuming. The choice of these typical reference spectra is based on their representativeness for the whole 2007 dataset, with respect to the solar zenith angle (SZA), the retrieved profile shape and the DOFS. Table 3 lists the date, the optical bandpass (OBP) and the SZA for the reference spectra analyzed for each species, together with the RMS of the spectral fit residual, the DOFS and the corresponding partial column (PC) ranges when applying the OEM, IOA and TR.
For each molecule the RMS value and the integer nearest to the number of degrees of freedom for signal are the same for every method, whereas the partial column limits are slightly different. These limits correspond to the altitude ranges that comprise at least one degree of freedom for signal. In order to allow direct comparison of the OEM, IOA and TR partial columns, or in other words, to discuss the retrieval results in terms of partial columns with identical altitude boundaries, from now on, the altitude ranges are deduced from the averaging kernel matrices such that the sum of the diagonal elements of $\mathbf{A}$ is at least one for every method, thus possibly increasing some of the partial column widths. If the remaining diagonal elements add up to more than 0.6 , the resulting altitude range is considered as an additional partial column.

Figures 3, 5, 7 and 9 illustrate the single or multiple microwindow fits of $\mathrm{O}_{3}, \mathrm{~N}_{2} \mathrm{O}, \mathrm{CH}_{4}$, and $\mathrm{CO}$, respectively, for the reference spectra listed in Table 3, together with the residuals, computed as measured minus simulated transmission. Figures 4, 6, 8 and 10 show the corresponding averaging kernels and sensitivity curves (black dashed), calculated at each altitude as the sum of the row elements of $\mathbf{A}$. As explained in Sect. 2.2.3, for the TR retrievals the sensitivity is 1 at every altitude and therefore a redundant quantity in the discussion. For $\mathrm{O}_{3}$ the SNR and $\alpha$ are 150 and 1, respectively, for $\mathrm{N}_{2} \mathrm{O}$ they are 150 and 5 , for $\mathrm{CH}_{4}$ they are 250 and 3, and for $\mathrm{CO}$ they are 150 and 5 . As the reference spectra are carefully chosen, they represent the complete dataset well, and, in turn, their resulting vertical profiles have also been found to be representative. The retrieved vertical profiles will therefore not be shown individually.

For every target gas the spectral fits look very similar for each method. For $\mathrm{O}_{3}$ and $\mathrm{CO}$ the retrieved profile is similar for each method. For $\mathrm{N}_{2} \mathrm{O}$ and $\mathrm{CH}_{4}$ the OEM retrieved profile slightly oscillates near the surface, whereas the IOA profile is more stable. The TR profile of $\mathrm{CH}_{4}$ oscillates less than the OEM profile but more than the IOA profile. In order to confirm and to generalize this conclusion, Fig. 11 shows the $\mathrm{CH}_{4}$ vertical volume mixing ratio (VMR) profiles obtained with the OEM, IOA and TR, from the whole set of FTIR spectra taken at St.-Denis in 2007. In the troposphere the TR profiles are slightly more stable than the OEM and IOA profiles, whereas at higher altitudes they are less stable than the IOA profiles, but still more stable than the OEM profiles. Note that the two groups that can be distinguished most clearly in the case of IOA correspond to spectra recorded at a SZA smaller and larger than $49^{\circ}$, respectively. The reason for this effect is not yet understood.

Table 4 summarizes the mean DOFS, the mean number of iterations in the fit (ITER), the mean RMS values of the spectral fit residual, the mean total and partial column amounts (CA) (in molecules $\mathrm{cm}^{-2}$ ) and the mean daily relative standard deviation (STD) on the CA (in \%) for each molecule when applying the OEM, IOA and TR. The mean daily relative standard deviations are considered to provide a good measure for the quality of the retrieval method, because they 
Table 6. Impact of different choices of $\mathbf{S}_{\mathrm{a}}$ on the $\mathrm{O}_{3}$ total and partial columns retrieved with the OEM, IOA and TR, for the 2007 campaign data at Ile de La Réunion: mean daily relative STD and mean relative biases with respect to the retrieval with $10 \% \mathbf{S}_{\mathrm{a}}$.

\begin{tabular}{rrrrrr}
\hline Alt. range [km] & $\begin{array}{r}\text { STD [\%] 10\% } \mathbf{S}_{\mathrm{a}} \\
\text { OEM / IOA / TR }\end{array}$ & $\begin{array}{r}\text { STD [\%] 40\% } \mathbf{S}_{\mathrm{a}} \\
\text { OEM / IOA / TR }\end{array}$ & $\begin{array}{r}\text { Bias [\%] 40\% } \mathbf{S}_{\mathrm{a}} \\
\text { OEM / IOA / TR }\end{array}$ & $\begin{array}{r}\text { STD [\%] 80\% } \mathbf{S}_{\mathrm{a}} \\
\text { OEM / IOA / TR }\end{array}$ & $\begin{array}{r}\text { Bias [\%] 80\% } \mathbf{S}_{\mathrm{a}} \\
\text { OEM / IOA / TR }\end{array}$ \\
\hline $0.05-100$ & $0.32 / 0.35 / 0.31$ & $0.26 / 0.34 / 0.26$ & $-0.037 / 0.035 /-0.073$ & $0.25 / 0.28 / 0.25$ & $-0.26 / 0.21 /-0.17$ \\
$0.05-9.4$ & $0.90 / 0.99 / 0.89$ & $1.22 / 1.00 / 1.08$ & $-0.30 / 0.060 /-0.27$ & $1.68 / 1.14 / 1.30$ & $-0.96 / 0.18 /-0.58$ \\
$9.4-21.4$ & $0.98 / 1.38 / 0.99$ & $1.66 / 1.40 / 1.62$ & $-0.16 /-0.035 /-0.20$ & $2.21 / 1.60 / 1.92$ & $-0.58 / 0.26 /-0.40$ \\
$21.4-29.8$ & $0.57 / 0.61 / 0.54$ & $1.25 / 0.64 / 1.33$ & $0.18 / 0.067 / 0.14$ & $1.83 / 0.93 / 1.68$ & $0.20 / 0.20 / 0.20$ \\
$29.8-100$ & $0.88 / 1.02 / 0.74$ & $1.25 / 0.95 / 1.39$ & $-0.36 / 0.010 /-0.40$ & $2.41 / 0.78 / 2.15$ & $-1.09 / 0.21 /-0.81$ \\
\hline
\end{tabular}
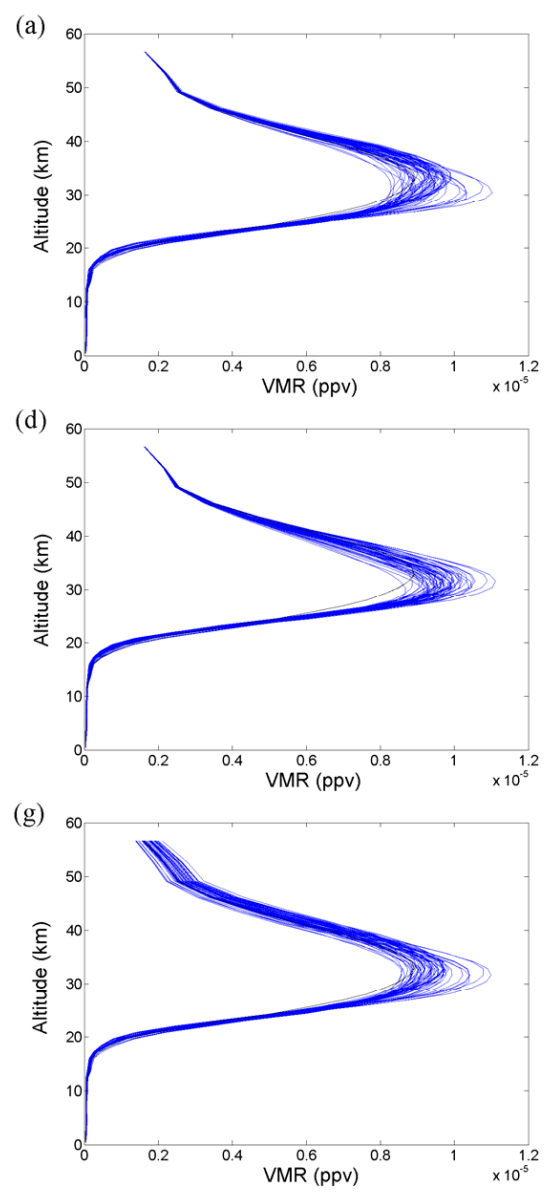
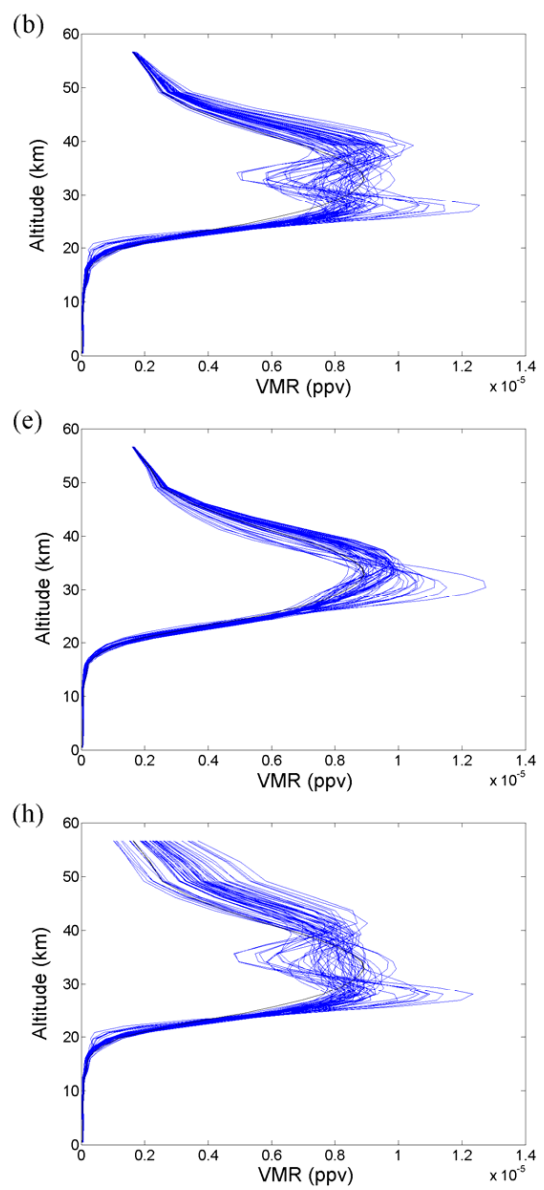

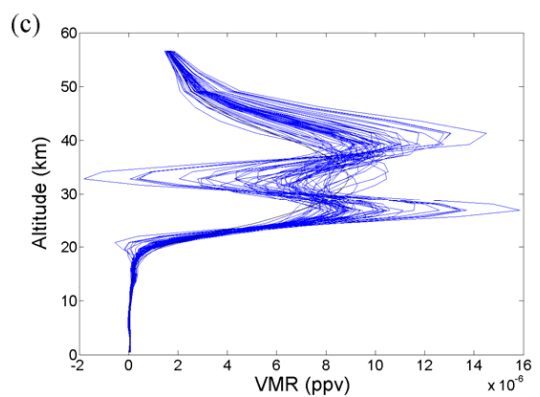

(f)
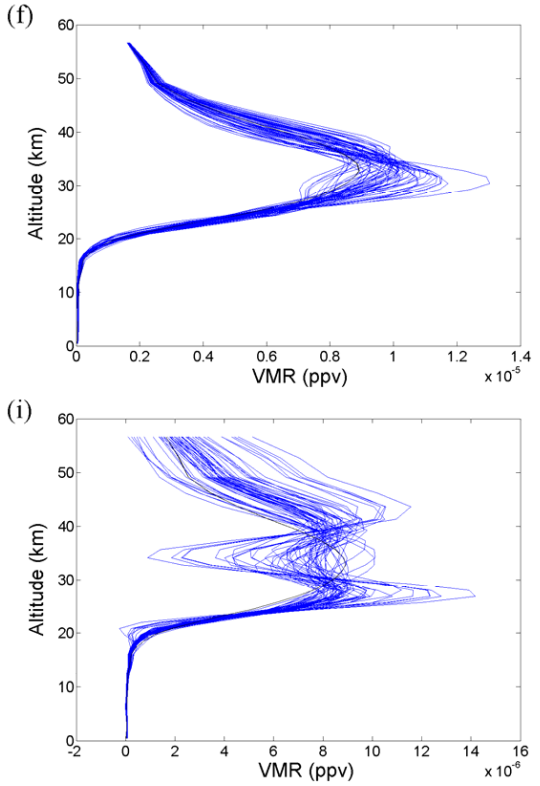

Fig. 14. $\mathrm{O}_{3}$ profiles from all spectra taken at St.-Denis during the 2007 campaign, retrieved with the OEM (a, b, c), IOA (d, e, f) and TR (g, h, i) with $\mathbf{S}_{\mathrm{a}}$ diagonal elements $10 \%, 40 \%$ and $80 \%$, respectively. The black line corresponds to the used a priori profile.

reflect the stability of the retrieved column amounts. Ideally, the latter do not change much over the course of a day, as the diurnal variations of the retrieved target molecules are supposed to be small. For all retrievals performed, we observe that the quality of the spectral fits - characterized by the RMS -, as well as the mean vertical column amount (VCA) and partial column amounts (PCA), are similar for all three methods. For $\mathrm{O}_{3}$ and $\mathrm{CO}$ the mean number of iterations before convergence is equal for each method, whereas for $\mathrm{N}_{2} \mathrm{O}$ and $\mathrm{CH}_{4}$ it is smaller for the IOA and TR. The information content - represented by the DOFS - is slightly smaller for the IOA. This is due to the fact that the IOA leaves out all components that do not contribute significantly to the information content. In general, this loss - between 0 and 0.5 
Table 7. Impact of different choices of $\boldsymbol{x}_{\mathrm{a}}$ on the $\mathrm{O}_{3}$ total and partial columns retrieved with the OEM, IOA and TR, for the 2007 campaign data at Ile de La Réunion: mean daily relative STD and mean relative biases with respect to the retrieval with $\boldsymbol{x}_{\mathrm{a}}$.

\begin{tabular}{rrrrrr}
\hline & $\begin{array}{r}\text { STD [\%] } \boldsymbol{x}_{\mathrm{a}} \\
\text { OEM / IOA / TR }\end{array}$ & $\begin{array}{r}\text { STD [\%] } 2 \boldsymbol{x}_{\mathrm{a}} \\
\text { OEM / IOA / TR }\end{array}$ & $\begin{array}{r}\text { Bias [\%] 2 } \boldsymbol{x}_{\mathrm{a}} \\
\text { OEM / IOA / TR }\end{array}$ & $\begin{array}{r}\text { STD [\%] 1/2 } \boldsymbol{x}_{\mathrm{a}} \\
\text { OEM / IOA / TR }\end{array}$ & $\begin{array}{r}\text { Bias [\%] 1/2 } \boldsymbol{x}_{\mathrm{a}} \\
\text { OEM / IOA / TR }\end{array}$ \\
\hline $0.05-100$ & $0.32 / 0.35 / 0.32$ & $0.30 / 0.35 / 0.29$ & $-0.23 /-0.47 /-0.0099$ & $0.33 / 0.34 / 0.33$ & $0.12 / 0.10 /-0.12$ \\
$0.05-9.4$ & $0.90 / 0.98 / 0.89$ & $0.93 / 0.94 / 0.86$ & $-0.34 /-0.53 /-0.044$ & $1.08 / 0.92 / 1.01$ & $0.12 /-0.049 /-0.14$ \\
$9.4-21.4$ & $1.15 / 1.35 / 1.12$ & $1.42 / 1.46 / 1.30$ & $-0.33 /-0.67 /-0.090$ & $1.01 / 0.49 / 1.27$ & $0.15 / 0.11 / 0.0061$ \\
$21.4-29.8$ & $0.67 / 0.60 / 0.61$ & $0.90 / 0.65 / 0.87$ & $-0.086 /-0.31 / 0.065$ & $0.50 / 0.36 / 0.59$ & $0.076 / 0.097 /-0.18$ \\
$29.8-100$ & $0.93 / 1.00 / 0.75$ & $1.09 / 1.20 / 0.73$ & $-0.49 /-0.67 /-0.11$ & $0.78 / 0.72 / 0.84$ & $0.19 / 0.12 /-0.075$ \\
\hline
\end{tabular}

Table 8. Mean relative differences with corresponding standard deviations (between brackets) between retrieved and "input" total and partial columns of $\mathrm{O}_{3}$ from simulated spectra.

\begin{tabular}{rrrr}
\hline Alt. range [km] & Rel. diff. [\%] OEM & Rel. diff. [\%] IOA & Rel. diff. [\%] TR \\
\hline $0.05-100$ & $0.11(0.087)$ & $0.11(0.092)$ & $0.12(0.064)$ \\
$0.05-9.4$ & $0.69(0.56)$ & $1.03(0.86)$ & $0.66(0.51)$ \\
$9.4-21.4$ & $1.82(0.62)$ & $1.78(0.60)$ & $1.86(0.50)$ \\
$21.4-29.8$ & $1.11(0.57)$ & $1.13(0.47)$ & $1.21(0.37)$ \\
$29.8-100$ & $0.70(0.60)$ & $0.63(0.51)$ & $0.72(0.37)$ \\
\hline
\end{tabular}

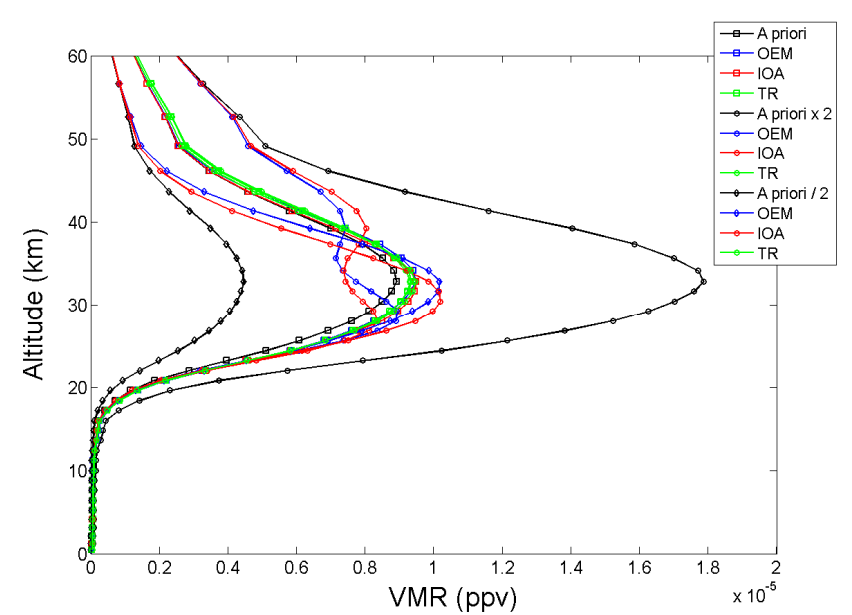

Fig. 15. $\mathrm{O}_{3}$ profile on 12 June 2007 at St.-Denis obtained with the original $\boldsymbol{x}_{\mathrm{a}}$ (squares), with $2 \boldsymbol{x}_{\mathrm{a}}$ (circles) and with $1 / 2 \boldsymbol{x}_{\mathrm{a}}$ (diamonds), retrieved with the OEM (blue), IOA (red) and TR (green), respectively. The black profiles are the respective a priori profiles.

- does not affect the number of partial columns that can be distinguished. For $\mathrm{O}_{3}, \mathrm{~N}_{2} \mathrm{O}$ and $\mathrm{CO}$ the mean daily relative standard deviations on the VCA are alike for each method, whereas for $\mathrm{CH}_{4}$ it is obviously smaller for the IOA and TR. For $\mathrm{CO}$ the mean daily relative standard deviations on the PCA are similar for each method. For $\mathrm{O}_{3}$ they are largest for the IOA, for $\mathrm{N}_{2} \mathrm{O}$ they are smaller for the IOA, and for $\mathrm{CH}_{4}$ they are smallest for TR.
Figure 12 shows the time series of the total and partial column amounts (in molecules $\mathrm{cm}^{-2}$ ) of $\mathrm{O}_{3}, \mathrm{~N}_{2} \mathrm{O}, \mathrm{CH}_{4}$ and $\mathrm{CO}$, respectively, during the FTIR campaign at St.-Denis in 2007, retrieved with the OEM, IOA and TR. For $\mathrm{O}_{3}$ and $\mathrm{CO}$ each method gives about the same partial and total column values, i.e. without significant bias. For $\mathrm{N}_{2} \mathrm{O}$ the partial and total columns are distributed in a slightly different way. The biases between the OEM and IOA total columns are about $-0.2 \%$ and the biases between the OEM and TR total columns are about $-0.15 \%$. The biases between the OEM and IOA first and second partial columns are -0.8 and $+0.8 \%$, respectively, whereas they are -0.5 and $+0.5 \%$ between the respective OEM and TR partial columns. For $\mathrm{CH}_{4}$ there is a systematic bias of the order of $+1.5 \%$ between the OEM and IOA daily mean first partial and total columns, while the bias between the OEM and TR column amounts is about $+1 \%$. So for the cases in which the IOA columns systematically deviate from the OEM columns, the same is observed for the TR columns, but with a smaller offset.

\subsubsection{Error budget evaluations}

For a detailed description of all error components quantifying the reliability of the retrieval results, we refer to Senten et al. (2008). In particular, the following error contributions are calculated: the smoothing error, the forward model parameter error, the measurement noise error, the errors due to the uncertainties in the temperature profile, in the solar zenith 
angle, in the interfering species' profiles, and in the intensity and pressure broadening of the target spectral lines, as well as the errors due to the uncertainties in the instrument line shape, i.e. the modulation amplitude and phase. As said before, all error components for the IOA and TR retrievals are calculated in the same way as for the OEM retrievals, using the appropriate averaging kernels and gain matrices. For the calculation of the smoothing error, we use the same $\mathbf{S}_{\mathrm{a}}$ matrices for each target species as in Senten et al. (2008). The covariance matrix used for the calculation of the error due to the temperature profile uncertainty is based on the differences between NCEP and ECMWF temperature profiles at St.-Denis. The covariance matrices used for the ILS uncertainty errors represent the degradation of the modulation efficiency and the evolution of the phase error. They are both calculated from the differences between the observed ILS functions - calculated with Linefit8 (Hase et al., 1999) - over a three months time period in 2007 at St.-Denis. The maximum uncertainty in the SZA was estimated at 0.2 degrees. The maximum uncertainties in the line intensity and pressure broadening of the spectral lines of the target molecule were derived from HITRAN 2008.

Table 5 gives an overview of the error budgets on the total and partial columns of $\mathrm{O}_{3}, \mathrm{~N}_{2} \mathrm{O}, \mathrm{CH}_{4}$ and $\mathrm{CO}$, when using the OEM, IOA and TR. More specifically, the smoothing error, the total random error without the smoothing component, the total random error, the total systematic error and the total error are shown. The individual contributions to the total random error are the forward model parameter error, the ILS errors, the temperature error, the measurement noise error, the SZA error, the interfering species errors, and the smoothing error, whereas the total systematic error includes the line intensity error and pressure broadening error. The complete table of all these individual contributions can be found in Appendix A.

Although at first sight each retrieval method behaves similarly regarding error budgets, we observe non-negligible differences.

For each species, except for $\mathrm{N}_{2} \mathrm{O}$, the smoothing error is smallest when applying the OEM, for the total as well as for the partial columns. The fact that the smoothing error is generally largest when using the IOA, is in agreement with the slightly smaller DOFS (see Table 3), or equivalently with the small loss of information with respect to the other two methods. For the $\mathrm{O}_{3}$ and $\mathrm{CH}_{4}$ total and partial columns the total random error without the smoothing component is smallest for the IOA, whereas for the $\mathrm{N}_{2} \mathrm{O}$ and $\mathrm{CO}$ columns it is smallest for TR. The same is observed for the total systematic error, except for the $\mathrm{N}_{2} \mathrm{O}$ and $\mathrm{CO}$ total columns for which the IOA seems to be better than TR. Note that the reduced random error for the IOA and TR columns - depending on the target gas - mainly comes from a decrease of the forward model parameter error, the measurement noise error and the temperature error (see Appendix A). As a result, for the $\mathrm{O}_{3}$ total and partial columns and for the $\mathrm{N}_{2} \mathrm{O}$ and $\mathrm{CO}$ total columns the total error is smallest for the IOA, while for the $\mathrm{N}_{2} \mathrm{O}$ and $\mathrm{CO}$ partial columns it is smallest for TR. For $\mathrm{CH}_{4}$ the total error is smallest for the OEM.

\section{Influence of a priori information}

One of the goals of implementing the IOA was to improve the robustness of the retrieval results. We therefore studied the impact of the choice of a priori information on the OEM, IOA and TR solutions. More specifically, we changed the diagonal elements of $\mathbf{S}_{\mathrm{a}}$ and looked at the VMR profiles obtained, at the DOFS, at the daily relative standard deviations on the total and partial column amounts and at the mean relative biases with respect to the original column values. In each case, the off-diagonal elements of $\mathbf{S}_{\mathrm{a}}$ are kept unchanged and are determined by a Gaussian correlation function with an inter-layer correlation length of $4 \mathrm{~km}$.

Table 6 shows the mean daily relative standard deviations (in \%) for the 2007 time series of the $\mathrm{O}_{3}$ total and partial column amounts (CA), when using $10 \%, 40 \%$ and $80 \%$ as priori uncertainties on the diagonal of $\mathbf{S}_{a}$, together with the mean relative biases (in \%) with respect to the original retrieval using $10 \% \mathbf{S}_{\mathrm{a}}\left(\mathrm{CA}_{\mathrm{ref}}\right)$. These biases are calculated as $100 *\left[\sum_{i=1}^{k}\left(\mathrm{CA}-\mathrm{CA}_{\text {ref }}\right) /\left(\left(\mathrm{CA}+\mathrm{CA}_{\text {ref }}\right) / 2\right)\right] / k$, with $k$ the number of measured spectra. Obviously, the mean relative biases on the total and partial column values are smaller for the IOA retrievals than for the OEM and TR retrievals. Hence, the net effect of more stable column amounts in the case of IOA prevails, especially when allowing greater a priori uncertainties on the profiles. In agreement with this finding, the mean daily relative standard deviations on the IOA column amounts vary less with a change of $\mathbf{S}_{\mathrm{a}}$ than those on the OEM and TR column amounts. For the above mentioned choices of $\mathbf{S}_{\mathrm{a}}$ the mean DOFS for the OEM retrieval results are 4.6, 6.0 and 6.7, respectively, for the IOA results they are 3.9, 5.2 and 5.9, respectively, and for the TR retrievals they are 4.6, 6.0 and 6.5, respectively. Thus, for each method, the information content varies in the same way with respect to the applied a priori uncertainty, as expected.

As an illustration, Fig. 13 shows the OEM, IOA and TR $\mathrm{O}_{3}$ profile at St.-Denis on 12 June 2007, obtained when using $\mathbf{S}_{\mathrm{a}}$ with on its diagonal $10 \%, 40 \%$ and $80 \%$, respectively. Note that for the TR retrievals, changing $\mathbf{S}_{\mathrm{a}}$ corresponds to changing $\alpha$. In particular, in our test case of $\mathrm{O}_{3}(\mathrm{SNR}=150)$, the mentioned diagonal values $10 \%, 40 \%$ and $80 \%$ correspond to $\alpha$ equal to $1,0.05$ and 0.02 , respectively. It is clear that when we apply a too large variability on the volume mixing ratios, i.e. $40 \%$ or more in this example, the retrieved profile deviates strongly in the case of OEM and to a lesser extent in the case of TR, whereas it stays reasonably good for the IOA. This difference becomes larger as we increase the a priori uncertainty. 
Figure 14 shows the OEM, IOA and $\mathrm{TR}_{3}$ profiles from all 2007 spectra at St.-Denis for $10 \%, 40 \%$ and $80 \% \mathbf{S}_{a}$, confirming the statements above. Thus, IOA retrievals are less sensitive to the choice of the a priori covariance matrix than OEM and TR retrievals. This can be understood by the fact that the IOA extracts the real information out of the measurements and is therefore less affected by unrealistic a priori choices.

Next, we looked at the same characteristics of the OEM, IOA and TR retrievals, but when changing $\boldsymbol{x}_{\mathrm{a}}$ instead of $\mathbf{S}_{\mathrm{a}}$. Table 7 shows the mean daily relative standard deviations (in $\%$ ) on the 2007 time series of $\mathrm{O}_{3}$ total and partial column amounts, when using $\boldsymbol{x}_{\mathrm{a}}, 2 \boldsymbol{x}_{\mathrm{a}}$ and $1 / 2 \boldsymbol{x}_{\mathrm{a}}$ as a priori profile, together with the mean relative biases (in \%) with respect to the original retrieval using $\boldsymbol{x}_{\mathrm{a}}$. The mean relative daily standard deviations appear to be most steady in the case of TR and, consistently, also the relative biases are smallest for the TR retrievals.

By means of example, Fig. 15 shows the OEM, IOA and $\mathrm{TR} \mathrm{O}_{3}$ profile on 12 June 2007, obtained with the original $\boldsymbol{x}_{\mathrm{a}}$ and with $2 \boldsymbol{x}_{\mathrm{a}}$ and $1 / 2 \boldsymbol{x}_{\mathrm{a}}$, respectively. Clearly, the TR retrieval is less affected by the change of the a priori profile than the OEM and IOA retrieval. This is logical, as the TR vertical profile with $\mathbf{L}_{1}$ as regularization matrix is by definition mainly influenced by the shape of the a priori profile, rather than by its magnitude. Note that this second test tells us something about the importance of the choice of $\boldsymbol{x}_{\mathrm{a}}$ for the three methods, but nothing about the robustness of the retrieved profile.

Finally, we have also tested the sensitivity of the OEM, IOA and TR retrieval results to the choice of the retrieval grid, varying from a fine 44 layer grid to a coarse 7 layer grid. We have found the effect on the retrieval results to be similar for each method. More specifically, we observed a decreasing accuracy for a decreasing number of layers.

\section{Theoretical study}

To quantify the additional benefit of the IOA a theoretical test has been done based on synthetic spectra. Hereto we created a large set of realistic vertical ozone profiles, and calculated the corresponding spectra using our forward model. Then we added Gaussian distributed random noise to these spectra, based on realistic SNR values, in agreement with the SNR values observed in our Réunion spectra. As such we generated a realistic ensemble of virtual measurements. We then performed OEM, IOA and TR retrievals of $\mathrm{O}_{3}$ from these spectra with the same retrieval parameters as used before for the real observed spectra, and evaluated their respective reconstructions of the initial vertical profiles. More specifically, each retrieved total and partial column amount has been compared to the corresponding column value adopted in the forward model.
The results of these comparisons are shown in Table 8, as mean relative differences (in \%), together with the standard deviations (between brackets). As for the total columns we see that the OEM and IOA slightly better reproduce the original values than TR (i.e. mean relative differences of 0.11 , 0.11 and $0.12 \%$, respectively), although with larger standard deviations (i.e. $0.09,0.09$ and 0.06 , respectively). For the second and fourth column, the IOA reproduces the input values best, whereas the first and third partial columns are better reconstructed by the TR and OEM, respectively. The standard deviations are smallest in the case of TR for each partial column. This test shows that the IOA is slightly better in reproducing the original input information, while TR produces more stable results.

\section{Conclusions}

In this paper we have shown the application of the information operator approach (IOA) to the retrieval of the vertical distribution of atmospheric constituents from groundbased high spectral resolution FTIR solar absorption measurements. All our tests have been performed on spectra taken at the southern hemisphere (sub)tropical site Ile de La Réunion in 2007. In addition, a theoretical study has been made, based on synthetic spectra. We have compared the IOA retrieval results for $\mathrm{O}_{3}, \mathrm{~N}_{2} \mathrm{O}, \mathrm{CH}_{4}$ and $\mathrm{CO}$ with those obtained when using the optimal estimation method (OEM) and Tikhonov regularization (TR). Our findings prove that the IOA allows the derivation of more stable vertical profiles and total and partial column amounts than the OEM for the atmospheric species investigated, without significant loss of information. Moreover, the IOA is less sensitive to the choice of the a priori covariance matrix. Regarding the error budgets on the total and partial columns we can conclude that the IOA and TR generally perform better than the OEM.

Comparisons of the OEM and IOA retrieval results with those obtained with TR have shown that the stability of the TR column values is somewhat better than the OEM and IOA stability. The information content of the IOA retrievals is slightly smaller than the information content of the OEM and TR retrievals, a quantity being about the same for the last two methods. So, the IOA performs well, i.e. similar to TR, and has some advantages with respect to the OEM, especially regarding profile stability and error budget evaluations.

Based on this study, we can conclude that the IOA applied onto the OEM is a valuable alternative for the retrieval of vertical profile information of trace gases in the atmosphere from ground-based FTIR solar absorption measurements. It behaves better than the OEM from several points of view, but the significance of the improvements depends on the target species and on the chosen a priori information. The approach can easily be implemented in the existing retrieval codes that are used in the Infrared Working Group of NDACC. 
Table A1. Summary of all individual error contributions (i.e. fit parameters, smoothing, measurement noise, temperature, intensity, pressure broadening, SZA, empirical apodization, empirical phase, and interfering species error) for each target species retrieved with the OEM, IOA and TR.

\begin{tabular}{|c|c|c|c|c|c|c|c|c|c|c|c|}
\hline Molec. & $\begin{array}{l}\text { Alt. range } \\
{[\mathrm{km}]}\end{array}$ & $\begin{array}{l}\text { Fit. } \\
\text { param. } \\
{[\%]}\end{array}$ & $\begin{array}{l}\text { Smooth. } \\
{[\%]}\end{array}$ & $\begin{array}{l}\text { Meas. } \\
\text { noise } \\
{[\%]}\end{array}$ & $\begin{array}{l}\text { Temp. } \\
{[\%]}\end{array}$ & $\begin{array}{l}\text { Inten. } \\
{[\%]}\end{array}$ & $\begin{array}{l}\text { Press. } \\
\text { broad. } \\
{[\%]}\end{array}$ & $\begin{array}{l}\text { SZA } \\
{[\%]}\end{array}$ & $\begin{array}{l}\text { Emp. } \\
\text { apod. } \\
{[\%]}\end{array}$ & $\begin{array}{l}\text { Emp. } \\
\text { phase } \\
{[\%]}\end{array}$ & $\begin{array}{l}\text { Total } \\
\text { in- } \\
\text { terf. } \\
{[\%]}\end{array}$ \\
\hline & & $\begin{array}{l}\text { OEM/ } \\
\text { IOA/ } \\
\text { TR }\end{array}$ & $\begin{array}{l}\text { OEM/ } \\
\text { IOA/ } \\
\text { TR }\end{array}$ & $\begin{array}{l}\text { OEM/ } \\
\text { IOA/ } \\
\text { TR }\end{array}$ & $\begin{array}{l}\text { OEM/ } \\
\text { IOA/ } \\
\text { TR }\end{array}$ & $\begin{array}{l}\text { OEM/ } \\
\text { IOA/ } \\
\text { TR }\end{array}$ & $\begin{array}{l}\mathrm{OEM} / \\
\mathrm{IOA} / \\
\mathrm{TR}\end{array}$ & $\begin{array}{l}\mathrm{OEM} / \\
\mathrm{IOA} / \\
\mathrm{TR}\end{array}$ & $\begin{array}{l}\text { OEM/ } \\
\text { IOA/ } \\
\text { TR }\end{array}$ & $\begin{array}{l}\text { OEM/ } \\
\text { IOA/ }\end{array}$ & $\begin{array}{l}\text { OEM/ } \\
\text { IOA/ } \\
\text { TR }\end{array}$ \\
\hline \multirow{15}{*}{$\mathrm{O}_{3}$} & \multirow[t]{3}{*}{$0.05-100$} & $0.0070 /$ & $0.44 /$ & $0.19 /$ & $0.60 /$ & $2.53 /$ & $0.22 /$ & $0.44 /$ & $0.00012 /$ & $0 /$ & $0.23 /$ \\
\hline & & $0.0017 /$ & $0.54 /$ & $0.14 /$ & $0.46 /$ & $1.70 /$ & $0.19 /$ & $0.39 /$ & $0.012 /$ & $0 /$ & $0.10 /$ \\
\hline & & 0.0077 & 0.51 & 0.20 & 0.60 & 2.83 & 0.22 & 0.44 & 0.00014 & 0 & 0.26 \\
\hline & \multirow[t]{3}{*}{$0.05-9.4$} & $0.0046 /$ & $6.70 /$ & $1.25 /$ & $0.23 /$ & $14.14 /$ & $2.27 /$ & $0.44 /$ & $0.00010 /$ & $0 /$ & $0.91 /$ \\
\hline & & $0.0034 /$ & $9.06 /$ & $1.13 /$ & $0.21 /$ & $12.34 /$ & $1.89 /$ & $0.56 /$ & $0.094 /$ & $0 /$ & $0.53 /$ \\
\hline & & 0.0058 & 7.14 & 1.19 & 0.22 & 14.00 & 2.23 & 0.44 & 0.00011 & 0 & 0.86 \\
\hline & \multirow[t]{3}{*}{$9.4-21.4$} & $0.071 /$ & $9.05 /$ & $1.89 /$ & $2.43 /$ & $27.08 /$ & $2.62 /$ & $0.44 /$ & $0.0014 /$ & $0 /$ & $1.23 /$ \\
\hline & & $0.00036 /$ & $10.71 /$ & $1.40 /$ & $1.37 /$ & $13.69 /$ & $1.36 /$ & $0.32 /$ & $0.21 /$ & $0 /$ & $1.06 /$ \\
\hline & & 0.064 & 10.31 & 1.64 & 2.19 & 23.66 & 2.26 & 0.44 & 0.0012 & 0 & 0.90 \\
\hline & \multirow{3}{*}{$21.4-29.8$} & $0.077 /$ & $5.56 /$ & $1.47 /$ & $2.20 /$ & $21.81 /$ & $1.85 /$ & $0.43 /$ & $0.0015 /$ & $0 /$ & $1.60 /$ \\
\hline & & $0.00023 /$ & 7.58 & $0.87 /$ & $1.25 /$ & $7.81 /$ & $0.73 /$ & $0.49 /$ & $0.13 /$ & $0 /$ & $0.70 /$ \\
\hline & & 0.064 & 6.70 & 1.18 & 1.86 & 17.34 & 1.50 & 0.43 & 0.0013 & 0 & 1.14 \\
\hline & \multirow[t]{3}{*}{$29.8-100$} & $0.062 /$ & $5.03 /$ & $1.37 /$ & $1.89 /$ & $13.78 /$ & $1.16 /$ & $0.46 /$ & $0.0013 /$ & $0 /$ & $0.69 /$ \\
\hline & & $0.0088 /$ & $6.57 /$ & $1.09 /$ & $1.29 /$ & $7.71 /$ & $0.76 /$ & $0.18 /$ & $0.058 /$ & $0 /$ & $1.10 /$ \\
\hline & & 0.041 & 6.34 & 1.10 & 1.63 & 9.72 & 0.84 & 0.44 & 0.00087 & 0 & 0.093 \\
\hline \multirow{12}{*}{$\mathrm{N}_{2} \mathrm{O}$} & \multirow[t]{3}{*}{$0.05-100$} & $0.32 /$ & $0.10 /$ & $0.072 /$ & $0.19 /$ & $2.34 /$ & $0.85 /$ & $0.31 /$ & $0.00053 /$ & $0.0027 /$ & $0.041 /$ \\
\hline & & $0.12 /$ & $0.27 /$ & $0.060 /$ & $0.054 /$ & $2.57 /$ & $0.60 /$ & $0.32 /$ & $0.00050 /$ & $0.0072 /$ & $0.028 /$ \\
\hline & & 0.011 & 0.073 & 0.055 & 0.082 & 2.62 & 0.57 & 0.31 & 0.00023 & 0.0029 & 0.020 \\
\hline & \multirow[t]{3}{*}{$0.05-5.8$} & $0.73 /$ & $0.55 /$ & $0.28 /$ & $0.59 /$ & $4.22 /$ & $3.38 /$ & $0.31 /$ & $0.00087 /$ & $0.0055 /$ & $0.19 /$ \\
\hline & & $0.19 /$ & $1.36 /$ & $0.25 /$ & $0.39 /$ & $3.52 /$ & $3.22 /$ & $0.35 /$ & $0.0017 /$ & $0.029 /$ & $0.18 /$ \\
\hline & & 0.040 & 0.39 & 0.20 & 0.50 & 3.55 & 3.05 & 0.32 & 0.00035 & 0.0072 & 0.13 \\
\hline & \multirow[t]{3}{*}{$5.8-15.4$} & $1.19 /$ & $0.72 /$ & $0.34 /$ & $0.28 /$ & $2.15 /$ & $4.80 /$ & $0.32 /$ & $0.0017 /$ & $0.012 /$ & $0.23 /$ \\
\hline & & $0.30 /$ & $2.18 /$ & $0.32 /$ & $0.14 /$ & $2.52 /$ & $4.45 /$ & $0.24 /$ & $0.0038 /$ & $0.057 /$ & $0.21 /$ \\
\hline & & 0.11 & 0.65 & 0.22 & 0.23 & 2.58 & 4.37 & 0.31 & 0.0018 & 0.025 & 0.16 \\
\hline & \multirow[t]{3}{*}{$15.4-100$} & $2.76 /$ & $1.39 /$ & $0.55 /$ & $0.15 /$ & $9.31 /$ & $8.51 /$ & $0.26 /$ & $0.0034 /$ & $0.012 /$ & $0.29 /$ \\
\hline & & $0.70 /$ & $4.84 /$ & $0.58 /$ & $1.09 /$ & $3.23 /$ & $4.53 /$ & $0.46 /$ & $0.012 /$ & $0.16 /$ & $0.17 /$ \\
\hline & & 0.34 & 1.47 & 0.35 & 0.89 & 2.29 & 3.34 & 0.31 & 0.0080 & 0.098 & 0.075 \\
\hline \multirow{9}{*}{$\mathrm{CH}_{4}$} & \multirow[t]{3}{*}{$0.05-100$} & $0.11 /$ & $0.22 /$ & $0.29 /$ & $0.80 /$ & $4.69 /$ & $1.15 /$ & $0.36 /$ & $0.000074 /$ & $0 /$ & $0.21 /$ \\
\hline & & $0.095 /$ & $1.09 /$ & $0.25 /$ & $0.80 /$ & $6.22 /$ & $3.79 /$ & $0.47 /$ & $0.000086 /$ & $0 /$ & $0.12 /$ \\
\hline & & 0.062 & 0.31 & 0.26 & 0.80 & 4.92 & 1.71 & 0.37 & 0.00025 & 0 & 0.13 \\
\hline & \multirow[t]{3}{*}{$0.05-9.4$} & $0.17 /$ & $0.41 /$ & $0.62 /$ & $0.64 /$ & $7.12 /$ & $2.50 /$ & $0.37 /$ & $0.0013 /$ & $0 /$ & $0.46 /$ \\
\hline & & $0.11 /$ & $2.29 /$ & $0.24 /$ & $0.75 /$ & $6.27 /$ & $4.08 /$ & $0.48 /$ & $0.00076 /$ & $0 /$ & $0.11 /$ \\
\hline & & 0.17 & 0.64 & 0.53 & 0.64 & 7.21 & 2.75 & 0.37 & 0.00072 & 0 & 0.29 \\
\hline & \multirow[t]{3}{*}{$9.4-100$} & $0.59 /$ & $0.60 /$ & $0.58 /$ & $1.15 /$ & $5.62 /$ & $5.47 /$ & $0.33 /$ & $0.0031 /$ & $0 /$ & $0.34 /$ \\
\hline & & $0.15 /$ & $2.91 /$ & $0.35 /$ & $0.91 /$ & $6.10 /$ & $3.16 /$ & $0.44 /$ & $0.0021 /$ & $0 /$ & $0.18 /$ \\
\hline & & 0.58 & 0.61 & 0.51 & 1.16 & 6.02 & 5.51 & 0.37 & 0.0024 & 0 & 0.27 \\
\hline \multirow{12}{*}{$\mathrm{CO}$} & \multirow[t]{3}{*}{$0.05-100$} & $0.076 /$ & $0.15 /$ & $0.19 /$ & $1.22 /$ & $3.44 /$ & $0.75 /$ & $0.31 /$ & $0.00069 /$ & $0 /$ & $0.23 /$ \\
\hline & & $0.017 /$ & $0.15 /$ & $0.17 /$ & $1.16 /$ & $2.83 /$ & $0.53 /$ & $0.32 /$ & $0.00050 /$ & $0 /$ & $0.14 /$ \\
\hline & & 0.013 & 0.37 & 0.14 & 1.10 & 2.91 & 0.34 & 0.32 & 0.00025 & 0 & 0.10 \\
\hline & \multirow[t]{2}{*}{$0.05-2.6$} & $0.34 /$ & $1.92 /$ & $1.68 /$ & $3.36 /$ & $28.82 /$ & $8.89 /$ & $0.29 /$ & $0.0026 /$ & $0 /$ & $2.19 /$ \\
\hline & & $0.12 /$ & $2.45 /$ & $1.46 /$ & $2.58 /$ & $22.89 /$ & $7.68 /$ & $0.28 /$ & 0.0017/ & $0 /$ & $2.30 /$ \\
\hline & & 0.062 & 3.94 & 1.04 & 2.63 & 15.44 & 6.06 & 0.27 & 0.00032 & 0 & 1.83 \\
\hline & $2.6-9.4$ & $0.20 /$ & $2.22 /$ & $1.61 /$ & $0.50 /$ & $35.00 /$ & $8.05 /$ & $0.33 /$ & $0.0012 /$ & $0 /$ & $1.36 /$ \\
\hline & & $0.13 /$ & $2.67 /$ & $1.38 /$ & $0.77 /$ & 26.64/ & $6.04 /$ & $0.30 /$ & $0.0024 /$ & $0 /$ & $1.42 /$ \\
\hline & & 0.051 & 4.16 & 0.69 & 0.67 & 15.53 & 3.38 & 0.32 & 0.00057 & 0 & 0.71 \\
\hline & $9.4-100$ & $0.34 /$ & $2.18 /$ & $1.56 /$ & $1.17 /$ & $33.16 /$ & $7.44 /$ & $0.30 /$ & $0.0030 /$ & $0 /$ & $1.11 /$ \\
\hline & & $0.16 /$ & $2.47 /$ & $1.49 /$ & $0.79 /$ & $22.26 /$ & $5.04 /$ & $0.37 /$ & $0.0039 /$ & $0 /$ & $1.13 /$ \\
\hline & & 0.098 & 4.94 & 0.90 & 0.55 & 9.63 & 2.50 & 0.35 & 0.0016 & 0 & 0.89 \\
\hline
\end{tabular}


Acknowledgements. Thanks for financial support are due to the Belgian Federal Science Policy (Ministerial Order MO/35/024, ESAC II and AGACC contracts) and to the PRODEX Office. We also acknowledge the support of the European Commission through the GEOmon (Global Earth Observation and Monitoring) Integrated Project (contract number FP6-2005-Global-4-036677) and through the HYMN (HYdrogen, Methane and Nitrous oxide: trend variability, budgets and interactions with the biosphere) project (contract number GOCE-037048) under the 6th Framework Programme.

Edited by: C. von Savigny

\section{References}

Doicu, A., Hilgers, S., von Bargen, A., Rozanov, A., Eichmann, K.-U., von Savigny, C., and Burrows, J. P.: Information operator approach and iterative regularization methods for atmospheric remote sensing, J. Quant. Spectrosc. Ra., 103, 340-350, doi:10.1016/j.jqsrt.2006.05.002, 2007.

Duflot, V., Dils, B., Baray, J. L., De Mazière, M., Attié, J. L., Vanhaelewyn, G., Senten, C., Vigouroux, C., Clain, G., and Delmas, R.: Analysis of the origin of the distribution of CO in the subtropical southern Indian Ocean in 2007, J. Geophys. Res., 115, D22106, doi:10.1029/2010JD013994, 2010.

Golub, G. H. and Van Loan, C. F.: Matrix computations, The Johns Hopkins University Press, USA, 1983.

Hase, F., Blumenstock, T., and Paton-Walsh, C.: Analysis of the instrumental line shape of high-resolution Fourier transform IR spectrometers with gas cell measurements and new retrieval software, Appl. Opt., 38, 3417-3422, doi:10.1364/AO.38.003417, 1999.

Hase, F., Hannigan, J. W., Coffey, M. T., Goldman, A., Höpfner, M., Jones, N. B., Rinsland, C. P., and Wood, S. W.: Intercomparison of retrieval codes used for the analysis of high-resolution groundbased FTIR measurements, J. Quant. Spectrosc. Ra., 87, 25-52, doi:10.1016/j.jqstr.2003.12.008, 2004.

Hoogen, R., Rozanov, V. V., and Burrows, J. P.: Ozone profiles from GOME satellite data: description and first validation, J. Geophys. Res., 104, 8263-8280, doi:10.1029/1998JD100093, 1999.

Kozlov, V.: Design of Experiments Related to the Inverse Problem of Mathematical Physics, in: Mathematical Theory of Experiment Design, edited by: Ermakov, C. M., 216-246, Nauka, Moscow, 1983 (in Russian).

Kurylo, M. J. and Solomon, S.: Network for the Detection of Stratospheric Change, NASA Rep, Code EEU, 1990.

Kurylo, M. J.: Network for the detection of stratospheric change (NDSC), SPIE Proceedings 1991, Remote Sensing of Atmospheric Chemistry, 1491, 168-174, 1991.
Rinsland, C. P., Nicholas, B. J., Connor, B. J., Logan, J. A., Pougatchev, N. S., Goldman, A., Murcray, F. J., Stephen, T. M., Pine, A. S., Zander, R., Mahieu, E., and Demoulin, P.: Northern and southern hemisphere ground-based infrared spectroscopic measurements of tropospheric carbon monoxide and ethane, J. Geophys. Res., 103, 28197-28218, doi:10.1029/98JD02515, 1998.

Rodgers, C. D.: Inverse Methods for Atmospheric Sounding: Theory and Practice, Series on Atmospheric, Oceanic and Planetary Physics, Vol. 2, World Scientific, Singapore, 2000.

Rothman, L. S., Gordon, I. E., Barbe, A., Benner, D. C., Bernath, P. F., Birk, M., Boudon, V., Brown, L. R., Campargue, A., Champion, J.-P., Chance, K., Coudert, L. H., Danaj, V., Devi, V. M., Fally, S., Flaud, J.-M., Gamache, R. R., Goldmanm, A., Jacquemart, D., Kleiner, I., Lacome, N., Lafferty, W. J., Mandin, J.-Y., Massie, S. T., Mikhailenko, S. N., Miller, C. E., Moazzen-Ahmadi, N., Naumenko, O. V., Nikitin, A. V., Orphal, J., Perevalov, V. I., Perrin, A., Predoi-Cross, A., Rinsland, C. P., Rotger, M., Šimeková, M., Smith, M. A. H., Sung, K., Tashkun, S. A., Tennyson, J., Toth, R. A., Vandaele, A. C., and Vander Auwera, J.: The Hitran 2008 molecular spectroscopic database, J. Quant. Spectrosc. Ra., 110, 533-572, doi:10.1016/j.jqsrt.2009.02.013, 2009.

Schimpf, B. and Schreier, F.: Robust and efficient inversion of vertical sounding atmospheric high-resolution spectra by means of regularization, J. Geophys. Res., 102, 16037-16055, doi:10.1029/97JD00847, 1997.

Senten, C., De Mazière, M., Dils, B., Hermans, C., Kruglanski, M., Neefs, E., Scolas, F., Vandaele, A. C., Vanhaelewyn, G., Vigouroux, C., Carleer, M., Coheur, P. F., Fally, S., Barret, B., Baray, J. L., Delmas, R., Leveau, J., Metzger, J. M., Mahieu, E., Boone, C., Walker, K. A., Bernath, P. F., and Strong, K.: Technical Note: New ground-based FTIR measurements at Ile de La Réunion: observations, error analysis, and comparisons with independent data, Atmos. Chem. Phys., 8, 3483-3508, doi:10.5194/acp-8-3483-2008, 2008.

Shannon, C. E. and Weaver, W.: The Mathematical Theory of Communication, Univ. of Illinois Press, Urbana, 1949.

Steck, T.: Methods for determining regularization for atmospheric retrieval problems, Appl. Opt., 41, 1788-1797, doi:10.1364/AO.41.001788, 2002.

Tikhonov, A.: On the solution of incorrectly stated problems and a method of regularization, Dokl. Akad. Nauk SSSR, 151, 501504, 1963.

Vigouroux, C., De Mazière, M., Demoulin, P., Servais, C., Hase, F., Blumenstock, T., Kramer, I., Schneider, M., Mellqvist, J., Strandberg, A., Velazco, V., Notholt, J., Sussmann, R., Stremme, W., Rockmann, A., Gardiner, T., Coleman, M., and Woods, P.: Evaluation of tropospheric and stratospheric ozone trends over Western Europe from ground-based FTIR network observations, Atmos. Chem. Phys., 8, 6865-6886, doi:10.5194/acp-8-68652008, 2008. 